9-2011

\title{
Colored Overlays and the Reading Fluency of Middle School Students with Cognitive Disabilities
}

Emily Raymond

Cedarville University

Follow this and additional works at: http://digitalcommons.cedarville.edu/education_theses

Part of the Disability and Equity in Education Commons, and the Junior High, Intermediate, Middle School Education and Teaching Commons

\section{Recommended Citation}

Raymond, Emily, "Colored Overlays and the Reading Fluency of Middle School Students with Cognitive Disabilities" (2011). Master of Education Research Theses. 43.

http://digitalcommons.cedarville.edu/education_theses/43 
COLORED OVERLAYS AND THE READING FLUENCY OF MIDDLE SCHOOL STUDENTS WITH COGNITIVE DISABILITIES

An Applied Research Project submitted in partial fulfillment of the requirements for the degree of

Masters of Education

By

EMILY GRACE SULLIVAN RAYMOND

B.A. Education, Cedarville University, 2006

2011

Cedarville University 


\section{CEDARVILLE UNIVERSITY \\ SCHOOL OF GRADUATE STUDIES}

September 9, 2011

I HEREBY RECOMMEND THAT THE APPLIED RESEARCH PROJECT PREPARED UNDER MY SUPERVISION BY Emily Grace Sullivan Raymond ENTITLED Colored overlays and the reading fluency of middle school students with cognitive disabilities BE ACCEPTED IN PARTIAL FULFILLMENT OF THE REQUIREMENTS FOR THE DEGREE OF Master of Education

William E. Brown, Ph.D.

President

\section{Mark D. Meclain \\ Mark McClain, Ph.D}

Associate Academic Vice President College of Professions

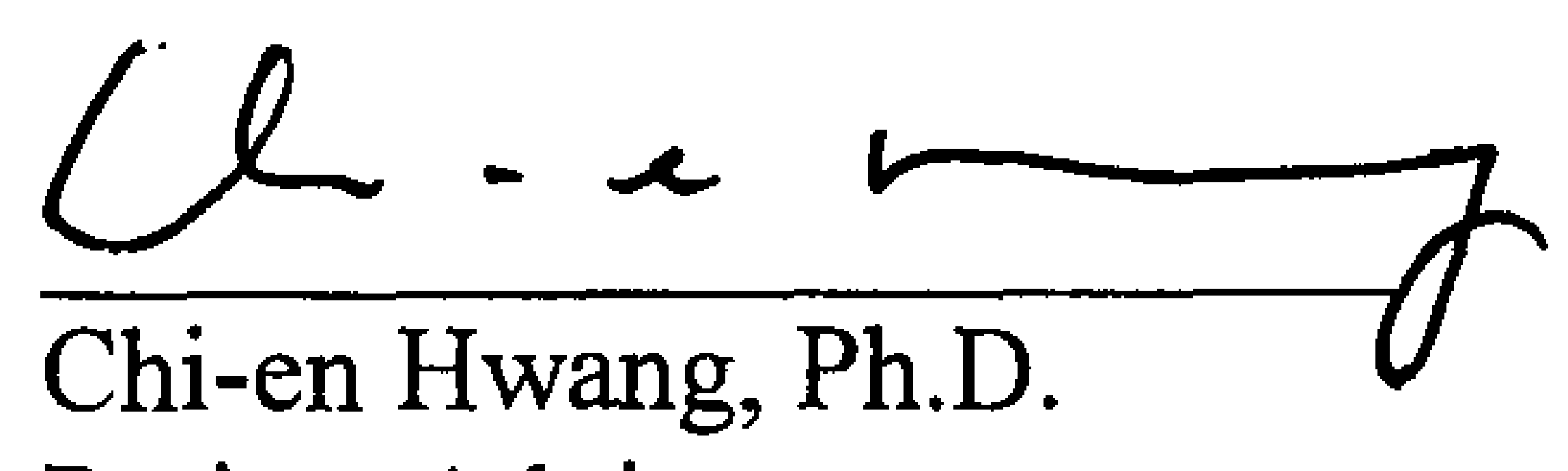

Project Advisor

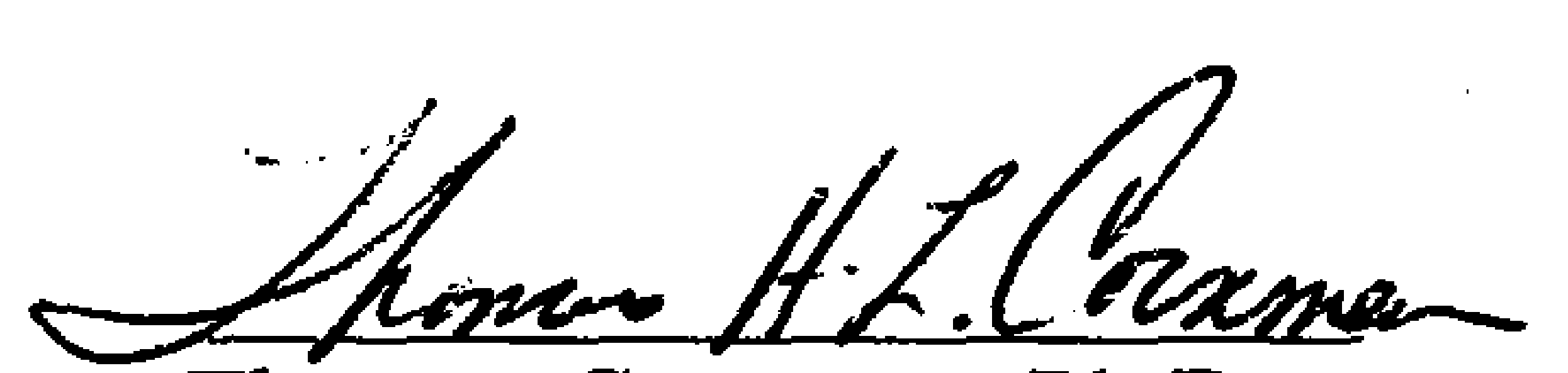

Thomas Cornman, Ph.D. Academic Vice President
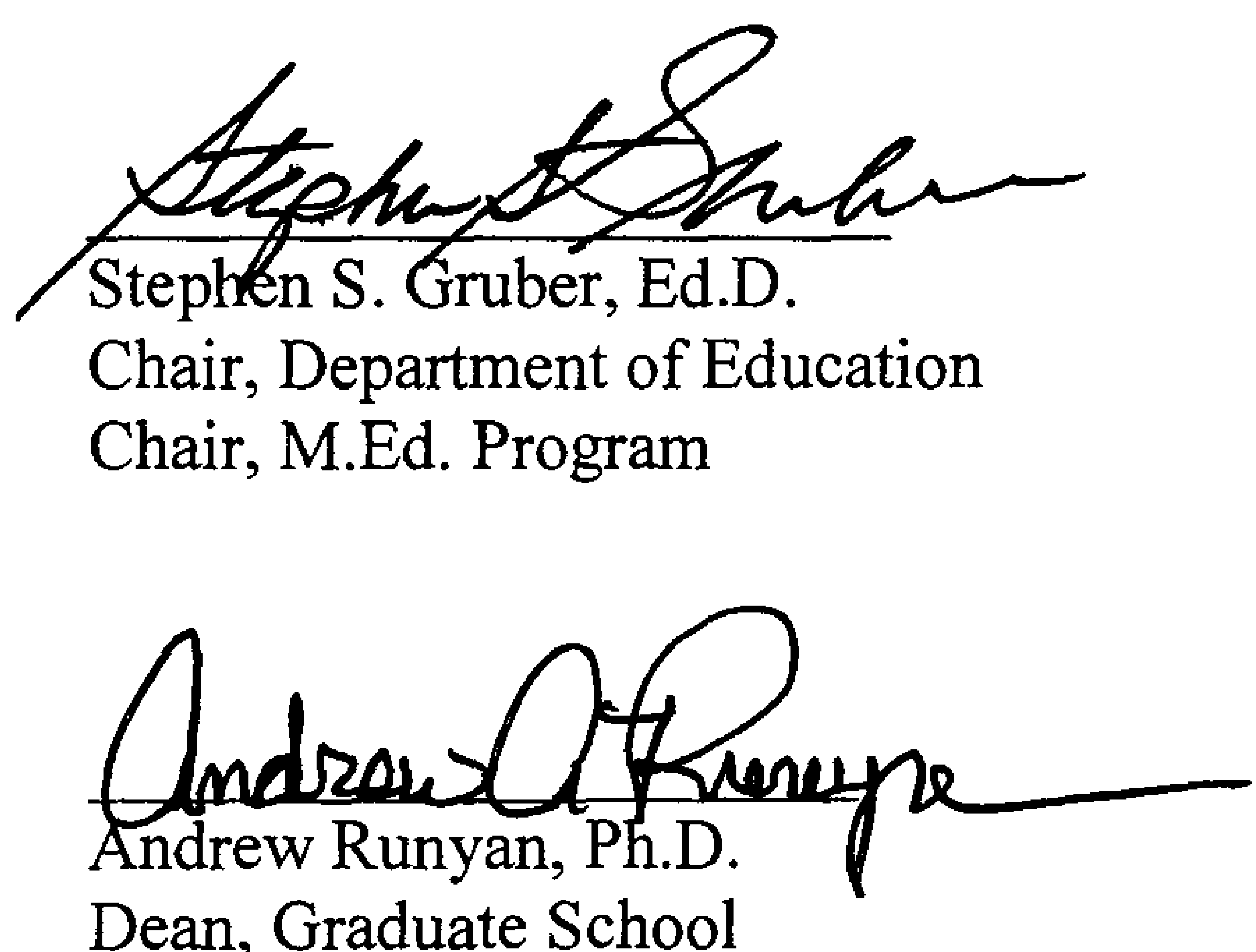

Associate Academic Vice President 


\begin{abstract}
Raymond, Emily G.S. M.Ed., Education Department, Cedarville University, 2011. Colored Overlays and the Reading Fluency of Middle School Students with Cognitive Disabilities.
\end{abstract}

Reading is an essential life skill that is a struggle for many students with cognitive disabilities. This quantitative study will examine the effects of colored overlay on the reading fluency of students with cognitive disabilities compared to students with Specific Reading Disabilities. The experiment is an ABA design to test for reversal where reading fluency baselines were collected before and after the application of the treatment of a colored overlay. Data is analyzed through multivariate tests of repeated measures ANOVA. Previous studies have shown colored overlays to be an effective intervention tool for increasing reading fluency rates in students with Specific Reading Disabilities. This study will seek to determine if those positive results can also be found for students with cognitive disabilities. 


\section{TABLE OF CONTENTS}

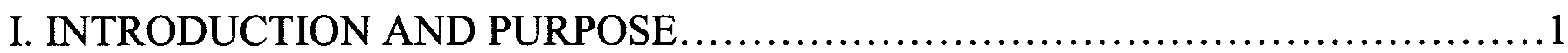

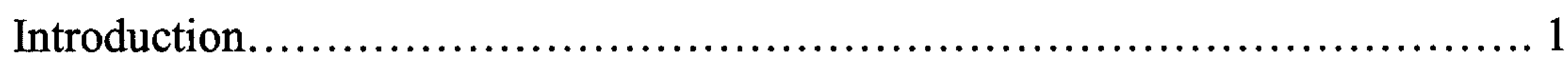

Definition of Terms............................................................ 3

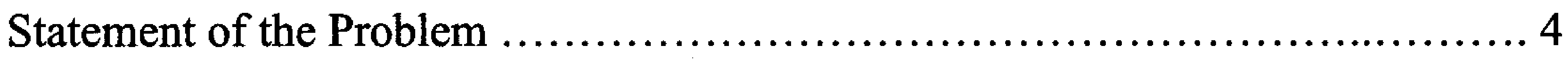

Scope of the Study and Delimitations....................................... 6

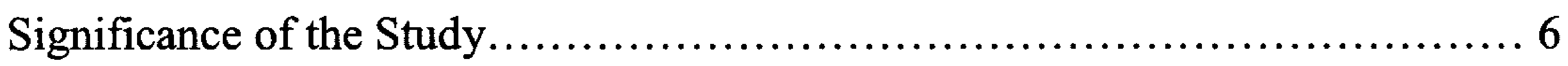

Methods of Procedure ............................................................. 8

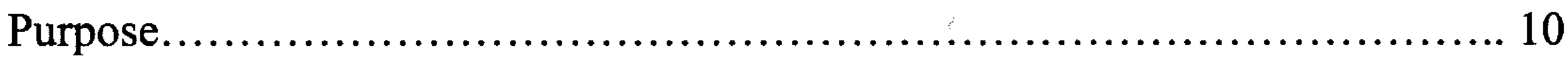

II. REVIEW OF THE LITERATURE ......................................... 12

Introduction...................................................................... 12

Past Research............................................................. 13

Current Research......................................................... 26

III. METHODOLOGY .......................................................... 36

Presentation of the Problem.................................................... 36

Presentation of the Hypotheses........................................... 36

Participants.......................................................... 37

Instruments............................................................... 38

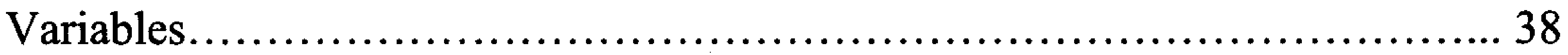

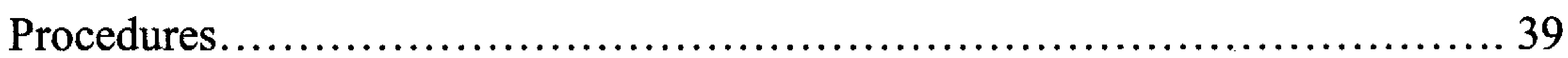

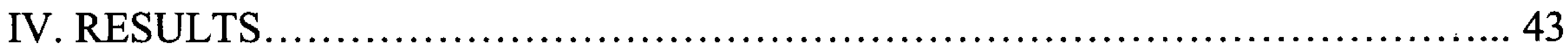




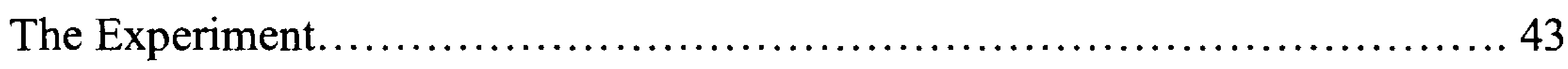

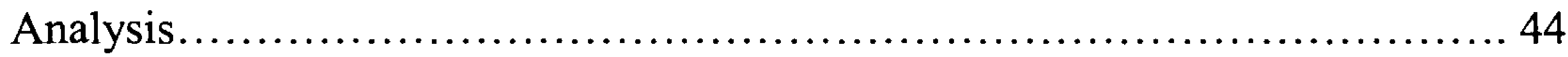

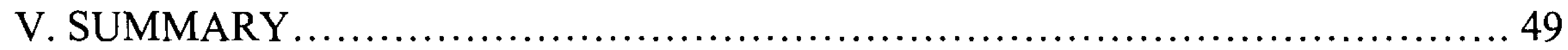

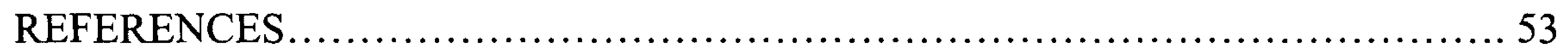




\section{LIST OF FIGURES}

Figure

1. Wilkins et al. (2001) image depicting reading speed........................... 15

2. Rate of reading test results in ABBA design illustrating effect of order.............. 17

3. Scatterplot comparing reading rate with use of control filter or colored overlay...... 19

4. Biobehavioral systems approach to identifying disability $\ldots \ldots \ldots \ldots \ldots \ldots \ldots \ldots \ldots \ldots \ldots \ldots \ldots \ldots$

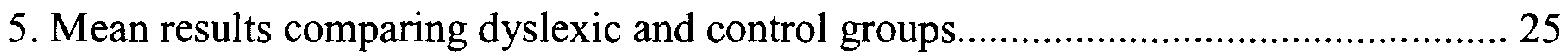

6. Timeline of testing sessions and mean results................................. 28

7. Mean reading rates comparing ASD and control groups with and without colored

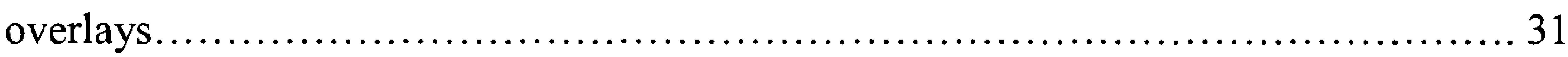

8. Mean reading rates comparing different types of overlays......................... 32

9. Line graph of Mean trial one, two, and three scores for groups one and two.......... 45 


\section{LIST OF TABLES}

Table

Page

1. Relationship between symptoms and predictive increase in reading rate........... 15

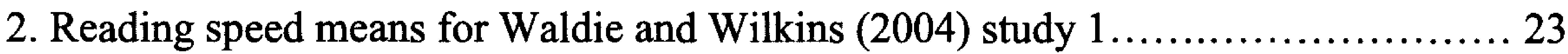

3. Reading speed means for Waldie and Wilkins (2004) study $2 \ldots \ldots \ldots \ldots \ldots \ldots \ldots \ldots . \ldots 23$

4. Mean reading speeds for normal, borderline, and Meares-Irlen participants.......... 26

5. Mean reading speeds comparing two systems of colored overlays..................30

6. Mean Trial one, two, and three scores for groups one and two................. 45 


\section{CHAPTER I: INTRODUCTION AND PURPOSE}

\section{Introduction}

Reading is an essential life skill where many students with special needs have a weakness. One must be able to read in order to navigate through daily life. For students and adults without special needs, reading is a skill that is often taken for granted. Reading comprehension is a focus of education at all levels. As students progress through the years, they are expected to comprehend more difficult text. Even at the college level, students are tested on their comprehension and analysis of what they have read.

A more basic skill in reading is fluency. Reading fluency is a primary focus in most elementary grades. As students progress into middle and high school, however, the focus shifts to comprehension. Many students with special needs do not master the skill of reading fluency and therefore struggle to comprehend what they are reading. If a student cannot read a passage fluently, comprehension will be even more of a challenge.

Reading fluency is a foundational ability that many students with special needs are lacking. If students are to comprehend what they read, they must be able to read with fluency. This study will examine one classroom intervention that previous studies (Ludlow, Wilkins \& Heaton, 2008; Northway, Manahilov \& Simpson, 2010; Trout \& Epstein, 2007) have shown to improve the reading fluency of students with autism spectrum disorders, specific reading disabilities, and ADHD. However, the focus of the 
study will be on students identified with cognitive disabilities. This study will seek to answer one primary question. Does the use of colored overlays increase the reading fluency rate using a timed running record of students with cognitive disabilities?

The participants of this study will be students in grades 6 to 8 who are identified with a cognitive disability. Many of these students participate in the general education classroom and are required to take the Ohio Achievement Assessment. Poor reading fluency affects student performance in class and on standardized tests. All students participating in the study have Individualized Education Program (IEP) goals addressing reading comprehension. Many do not have reading fluency goals, even though it is a skill they need in order to reach their comprehension goals.

The purpose of this study is to identify if the use of colored overlays is an effective classroom intervention tool to help improve the reading fluency of students with cognitive disabilities. The researcher was unable to find any previous studies addressing this intervention tool for this population of students. Being in the general curriculum classroom does not allow ample time for reading fluency interventions. A tool such as colored overlays, would be an easy and quick intervention that regular education teachers can use in their daily lessons. As students reach middle and high school, reading becomes a central activity in all content area classes. Even math requires students to read and comprehend story problems before being able to solve the problem using their math skills. Colored overlays would be a tool that teachers across all curricular areas could use. 


\section{Definition of Terms}

There are several terms that will be used throughout this study. Cognitive Disability refers to a diagnosed condition in which an individual has significant limitations in completing cognitive processes such as abstract thinking, conceptualizing, and recalling information (Braddock, Rizzolo, Thomopson \& Bell, 2004). The term cognitive disability can also be used to describe the condition of an individual with traumatic brain injury or Alzheimer's. For the purpose of this study the term will be used in reference to students who have been identified through the determination of a low IQ score by a psychologist.

Dyslexia is a term that is often misunderstood. The term dyslexia has come to refer to the reversal of letters when reading. Originally, this would be one type of dyslexia, but not the sole definition. Dyslexia initially meant a diagnosis of a general reading disability. Due to the common misconception of the definition, educators now use the term Specific Reading Disability. This study will use the term Specific Reading Disability (SRD) to avoid confusion. Students with Specific Reading Disabilities show a discrepancy between their IQ scores and their achievement in reading (Fletcher, Foorman \& Boudousquie, 2002).

Reading fluency is the rate at which a student can read a given text. In this study, reading fluency will be assessed using a timed running record. Students will be given a reading passage on their identified independent reading level according to their IEP. Students will read the passage aloud for one minute. The researcher will note any words read incorrectly. The number of words read correctly in one minute will be the reading fluency rate score for the student. 
Colored overlays are tinted, transparent sheets that can be used to reduce glare on white sheets of paper. The overlays also help to reduce the visual stress that some students experience when reading a text printed on white paper (Smith \& Wilkins, 2007). Students will be given a choice between sixteen different colored overlays.

\section{Statement of the Problem}

One purpose of this study is to fill in a research gap with the intervention tool of colored overlays. Many studies (Northway et al., 2010; Dain, Floyd \& Elliot, 2008; Ludlow et al., 2008; Trout et al., 2007; Carbo, 2010) have been conducted and suggest that the use of colored overlays increases the reading fluency of students with a variety of disabilities. Students with ADHD, Autism Spectrum Disorders, Specific Reading Disorders, and those considered at risk have participated in studies involving colored overlays. No studies were found that involved students with cognitive disabilities. This population of students may benefit from the use of colored overlays. This study hopes to identify the benefit or lack of benefit of colored overlays on the reading fluency of students with cognitive disabilities.

"Reading is a complex process of understanding written language which can be impaired at any of its visual, lexical-semantic and phonological processing stages." (Northway et al., 2010, 228) Educators must be able to address all of these possible affected areas in order to help students in learning to be comprehending readers. Teachers are trained in instructing students in phonics and semantics. However, teachers need tools to address the possible visual needs of students as related to reading. Colored overlays may be an effective tool to address some of those needs. 
Reading is an essential life skill that individuals use numerous times daily. Reading is required at school, home, and the workplace. All subject area classes ask students to read to some extent. In science, students must read and comprehend the textbook, lab experiment directions, and warning labels. Students must be able to read story problems in math before any computing even begins. In social studies, students have historical documents to read and textbook chapters. Language arts classes focus mainly on the skills of reading and writing.

At home, one reads recipes, magazines, and appliance instruction manuals. An adult living independently must be able to read bills and notices that come in the mail. At the workplace, different amounts of reading are required for different careers. Many employers communicate with employees through emails and memos posted in the workplace. Success in life can be influenced by the ability to read.

Reading is a skill that is automatic for many people. Unfortunately for students with cognitive disabilities, the ability to read and comprehend is often lacking. Reading fluency is vital for reading comprehension. If one is unable to read fluently, comprehension will suffer. At the middle school level, curriculum is focused on higher level thinking comprehension skills. Teachers do not have ample time to work on basic reading fluency skills with the students who are struggling. Many students with cognitive disabilities are in the general curriculum classroom and need to have reading fluency intervention. Colored overlays are a simple intervention tool that has been shown to work with students with SRD and other disabilities. This study will seek to determine if it is a worthwhile intervention to use with students with cognitive disabilities. 


\section{Scope of the Study and Delimitations}

The scope of this study will be two-fold. First, the researcher will seek to replicate the results of previous studies (Northway et al., 2010; Dain et al., 2008) suggesting that colored overlays improve the reading fluency of students with Specific Reading Disabilities. The control group will be comprised of students fitting this criteria as well as being matched demographically to those in the experimental group.

Second, the researcher will collect data to determine the benefit, if any, of colored overlays on the reading fluency of students with cognitive disabilities. Students with cognitive disabilities have many academic struggles, including reading. The researcher was unable to find previous studies of this kind and seeks to answer the question of benefit of colored overlays for students with cognitive disabilities. The answer to this question could impact the type of interventions used with students with cognitive disabilities.

This study is limited to the population of student with cognitive disabilities at one middle school. The participants will all be in grades 6 to 8 . All students at the school identified with a cognitive disability will participate in the study unless parental consent is not granted. The control group will be matched as closely as possible to the demographics of the experimental group.

\section{Significance of the Study}

This study is significant in the information that it will provide for teachers of students with cognitive disabilities. As previously discussed, reading is an essential life skill. State mandated curriculums limit teachers in the amount of time that can be devoted 
to reading fluency interventions. Colored overlays are a simple, quick, and inexpensive intervention. This study will seek to determine if it is an intervention that works for students with cognitive disabilities. If the study finds that there is no significant benefit of colored overlays for students with cognitive disabilities, teachers and school districts can seek more appropriate interventions. If this study is able to find significant benefit, teachers and districts will be able to utilize this intervention tool in the classroom.

Curriculum constraints and district budgets limit the extent to which certain interventions can be implemented. Many reading intervention programs require lengthy sessions and are very costly. Many districts do not have the money to invest in these programs. Time is also a valuable commodity in this time of high stakes testing and curriculum standards that are to be taught. Colored overlays would fit into both curriculum time limits and district budgets. It takes one session of about 10 minutes to work with a student in choosing the correct colored overlay for him or her. After a color is chosen, the student will continue to use that color of overlay consistently. When bought in bulk, colored overlays cost as little as $\$ 1.85$ per sheet (Irlen Institute).

By gathering data on colored overlays and the reading fluency of students with cognitive disabilities, the researcher hopes to be informed on the appropriateness of this intervention. The information from this study will be valuable to school districts, building principals, general education teachers, and special education teachers. Though the findings may not support colored overlays as being beneficial for students with cognitive disabilities, it is a step in the right direction. By confirming or eliminating this intervention for students with cognitive disabilities, teachers and school districts will be 
able to make an informed decision about the implementation of classroom interventions for students with cognitive disabilities.

\section{Methods of Procedure}

This quantitative study will employ a single-case experimental design with multiple baselines. The researcher will use an A-B-A design in order to test for reversal. The A-B-A design assesses for a baseline before and after the treatment of colored overlays is applied. The student will start by choosing a colored overlay based on the process Ludlow et al. (2008) used in the first experiment of their study. Students will be asked to look at text through two colored overlays side by side and determine which color provides the clearest view. The chosen color will be retained and a third color choice will replace the color not chosen. The participant will repeat this process through all sixteen colored overlay choices until only one remains. Once a color is chosen, the student will participate in the three timed running records. The participants will first be assessed using a timed running record of their fluency rate of reading text on plain white paper. Then reading fluency rate will be recorded with the use of the chosen colored overlay. The treatment will then be removed and a second baseline fluency rate will be obtained through the completion of a third timed running record of the fluency rate of reading from plain white paper.

The participants will be reading leveled passages that match their independent reading level. Independent reading level has been included in each student's IEP present levels. Students will be provided with 16 colored overlays from which to choose. Smith's 
et al. (2007) study results suggest that limiting color choices, only 5 choices, can also limit the benefit of colored overlays on reading fluency.

The 9 participants in the experimental group will be $6^{\text {th }}$ to $8^{\text {th }}$ grade students who have a cognitive disability. This group will be referred to as the experimental group or group one. The sample size will include the entire population of students with cognitive disabilities at Eaton Middle School in Eaton, Ohio, excluding any students whose parents do not give consent. Consent will be obtained through a passive consent form letter.

The control group for this study will include 9 students who have been identified as having a Specific Reading Disability. This group will be referred to as the control group or group two. The control group participants will be matched as closely as possible to the experimental group in the areas of grade, gender, ethnicity, and socioeconomic status. Consent will be obtained through a passive consent form letter, as with the experimental group. Studies (Northway et al., 2010; Dain et al., 2008; Carbo, 2010) have been used to show that students with Specific Reading Disabilities and reading difficulties benefit from the use of colored overlays. Students with SRD will be used in the control group as a comparison to those in the experimental group because of this past success with colored overlays. The researcher is seeking to determine if disability category influences the benefit of colored overlays on reading fluency.

Once data from the A-B-A design has been gathered, a quantitative analysis of the results will be completed using repeated measures ANOVA and looking at the means of the two groups. The researcher will be using an alpha level of $\leq .05$ to determine significance. The data will be analyzed to look for a significant increase in reading fluency rate in students with cognitive disabilities with the use of colored overlays. 


\section{Purpose}

This study was initially designed to address specific needs of a local school district. Eaton Middle School is a sixth through eighth grade building with around 500 students. It is located in Preble County, a rural area of southwest Ohio. The school has a special education population of about 70 students. Of those 70 students, only nine are identified as having a cognitive disability. About half of those students are required to take the Ohio Achievement Assessment. The other half is alternately assessed. Reading is a basic skill that is required for all the core content classes in middle school. Teachers do not focus their instructional time on basic reading skills such as fluency due to curriculum restraints and content standard requirements. Teachers in the building need to have an intervention tool to use with this population of students that will help increase reading fluency without taking up valuable instructional time. Colored overlays, if effective, are a quick and inexpensive tool that regular education teachers can use in their classroom to help improve the reading fluency of students with cognitive disabilities.

As the researcher began to review the literature addressing the intervention tool of colored overlays, a gap was found in the research. The researcher was unable to find any studies that addressed the population of students identified as having a cognitive disability. A secondary purpose of this study is to fill in the gap of previous research and begin to answer questions regarding the use of colored overlays and the reading fluency of students with cognitive disabilities. This study will seek to begin the research of using colored overlays with students with cognitive disabilities. 
Studies (Northway et al., 2010; Dain et al., 2008; Carbo, 2010) have shown that the use of a colored overlay is an effective intervention tool for students with Specific Reading Disabilities. Another purpose of this study is to determine if students with cognitive disabilities will respond in a similar way to this intervention tool. The control group will be comprised of students with Specific Reading Disabilities with the goal of replicating those previous studies to use as a comparison for the group of students with cognitive disabilities.

The primary goal of this study is to begin the research in the area of using colored overlays with students with cognitive disabilities. The researcher is seeking to answer questions specific to one middle school and the specific students at that school. The researcher will be able to determine what difference, if any, colored overlays create on the reading fluency of nine specific students at Eaton Middle School. A secondary goal is to create questions and interest surrounding this topic that can be addressed in future studies. This study will not be a comprehensive look at all questions related to this topic, but an introduction to begin the research that is needed to fill the gap that is found in current information available. 


\section{CHAPTER II: REVIEW OF THE LITERATURE}

\section{Introduction}

Many studies have been conducted researching the use of colored overlays or filters with students with special needs. Originally, this intervention was used with those identified as having a Meares-Irlen Syndrome, a visual stress disorder. It was later applied to those with a Specific Reading Disability. Much of the research in these areas is outdated and was completed in the 1990's and early 2000's. Though these studies are outdated, they hold historical importance when looking at the full implementation of the colored overlays in education. These studies will be discussed in order to offer background information and context.

More recently, research has been focused on expanding the use of colored overlays to include students identified as having other types of disabilities. Studies have been completed studying students identified with Autism Spectrum Disorders and ADHD. Studies have also been conducted looking at the use of this intervention with students identified as being at-risk or struggling readers. The researcher was unable to find any literature addressing the use of colored overlays with students with cognitive disabilities. Current research will be examined to provide a basis of understanding of the full scope of the uses of colored overlays. Some of these studies influenced the design of this researchers experiment and those decisions will be addressed. 


\section{Past Research}

O'Connor, Sofo, Kendall, and Olsen (1990) completed a study examining Scotopic Sensitivity or Meares- Irlen Syndrome. O'Connor et al. noted that individuals who complain of visual stress symptoms and benefitted from the use of colored overlays, could be diagnosed as having Scotopic Sensitivity. After identifying students with Scotopic Sensitivity, the researchers divided the students into several groups. In Group A, students would be assessed with the use of colored overlays. Group B would be assessed with the use of a clear overlay. O'Connor et al. looked at reading speed, accuracy, and comprehension. Group $\mathrm{C}$ would be given a colored overlay other than the color they preferred with which to be assessed.

All students in Group A showed an increase in reading speed and comprehension with the use of a colored overlay. For reading accuracy, 16 out of the 17 students in Group A showed an improvement with the use of a colored overlay. The results for Group B were varied with many even showing regression with the use of the clear overlay. Group $\mathrm{C}$ also showed varied results with some students regressing with the use of the colored overlay.

O'Connor et al. (1990) concluded that in order for a colored overlay to be effective, students must choose and appropriate color. Not one color will be adequate to address the needs of every student. Students must go through a process of identifying which color improves the text the best for them as individuals. It is important for educators wanting to use colored overlays to take the time to ensure that the students are matched appropriately to the color that best suits them. Though this study is very outdated, its findings are supported in later research that will also be discussed. 
In 2001, Wilkins, Lewis, Smith, Rowland, and Tweedie completed a study with the goal of replicating the finding of a 1999 study by Wilkins and Lewis with a larger sample size. This study included three separate experiments. The experiments did not look for data related to a specific disability. The study looked at children as a whole population and examined the response to the use of colored overlays.

The first experiment compared methods of choosing an overlay with 47 boys and 42 girls in $4^{\text {th }}$ to $6^{\text {th }}$ grade. This experiment involved three sessions of testing. In the first session, students chose a colored overlay in a group setting. In the second and third sessions, students were tested individually by two different instructors. This experiment was looking for consistency in color choice given different circumstances.

When looking at reading rates for the last two sessions, students who chose the same colored overlay, 46 children, showed the greatest increase in reading rate. The 19 students who chose a similar colored overlay in both sessions had a greater increase in reading rate than those 28 children who chose very different colors. The greater the consistency in color choice of the student, the greater increase in reading fluency rate with the use of a colored overlay.

When comparing testing outcomes of group sessions to individual sessions, the researchers found that students reported visual stress symptoms in all three sessions. There was not a significant difference in testing setting and symptoms reported. The study found that the greater number of symptoms reported, the greater the increase in reading fluency rate. 


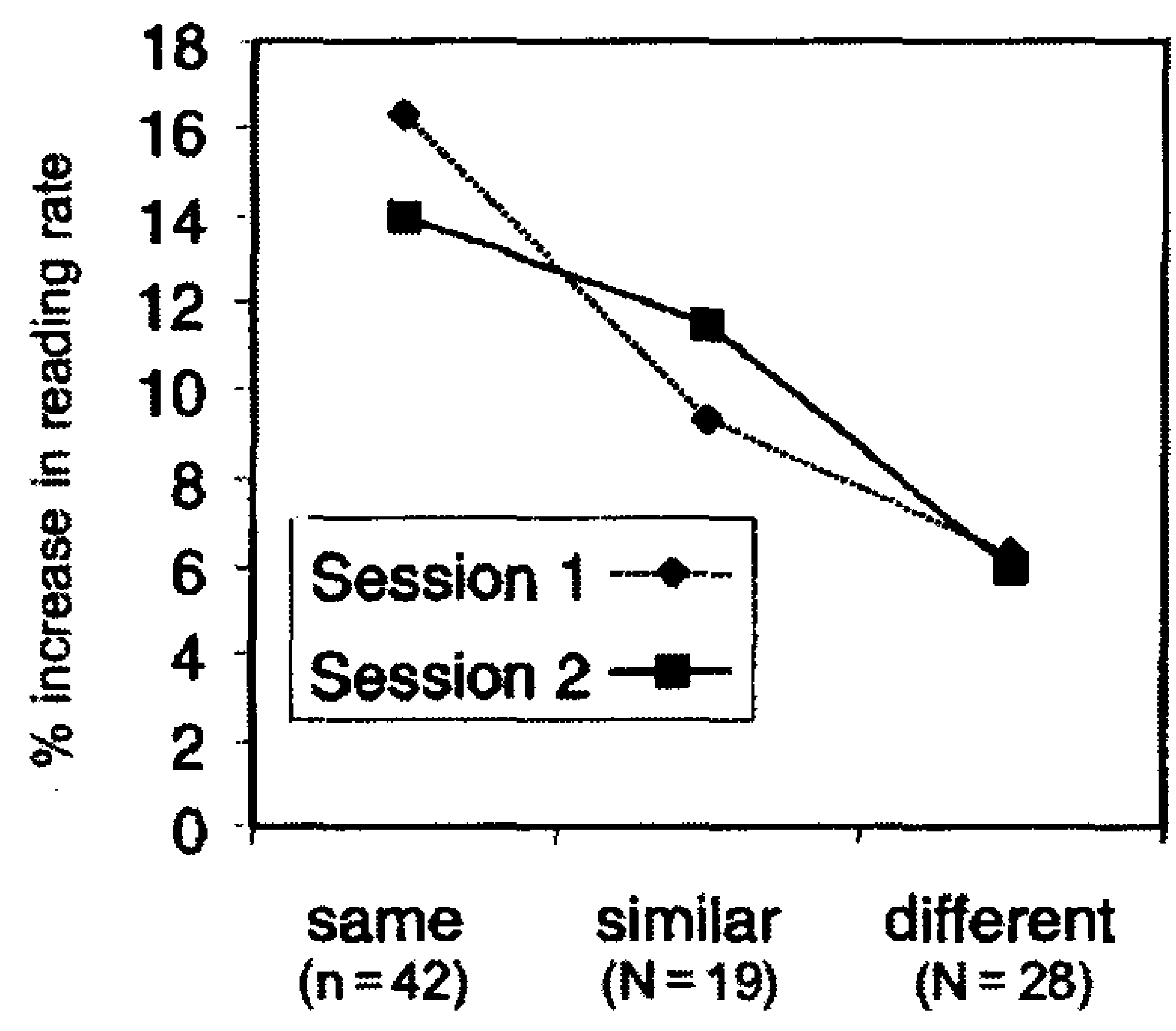

Colour choice

Figure 1. Wilkins et al. (2001) image displaying "improvement in reading speed with a chosen overlay in 78 children, shown separately for children who chose the same color on each of two tests, those who chose a similar color, and those who chose a different color" (Wilkins et al., 2001, 48).

Table 1

Wilkins et al. (2001) image displaying "the relationship between the number of symptoms reported in Study 1 and the sensitivity and specificity of the number of symptoms in predicting the percentage increase in reading rate with the overlay" (Wilkins et al., 2001, 50).

\begin{tabular}{|c|c|c|c|c|c|}
\hline & & \multicolumn{4}{|c|}{ Percentage increase in reading rate with the overlay } \\
\hline & & 10 & 20 & 30 & 40 \\
\hline \multicolumn{2}{|c|}{$\begin{array}{l}\text { Number of children showing } \\
\text { increase (Total } 70 \text { ) }\end{array}$} & 32 & 16 & 6 & 5 \\
\hline \multicolumn{6}{|l|}{ Symptoms } \\
\hline \multirow{2}{*}{2 or more } & Sensitivity & 72 & 75 & 100 & 100 \\
\hline & Specificity & 26 & 28 & 30 & 29 \\
\hline \multirow[t]{2}{*}{3 or more } & Sensitivity & 63 & 69 & 83 & 100 \\
\hline & Specificity & 50 & 48 & 47 & 48 \\
\hline \multirow[t]{2}{*}{4 or more } & Sensitivity & 53 & 56 & 83 & 100 \\
\hline & Specificity & 68 & 63 & 63 & 63 \\
\hline
\end{tabular}

When implementing the use of colored overlays with a large number of students, instructors can use a group testing method for helping students choose an appropriate color. According to Wilkins et al. (2001), this method is as effective as working with students individually. The greatest time investment a school has to make is in the initial 
screening and color choice process. By working with students in groups, the time can be reduced significantly.

The second experiment of the study was very similar to the first, with the exception of a larger sample size. This experiment included all 378 students in a middle school in Norfolk, UK. Students went through the process of choosing a colored overlay to use. Students were also assigned a random color for use. As with the first experiment, when the colors chosen and assigned were the same, rate increase was the greatest. If the random color was different from the chosen color, the rate increase was the least. This reinforces the conclusion that color choice is an important process when using colored overlays as an intervention tool.

The final experiment of the study looked at the prevalence of improvement in reading rate for students using colored overlays. This study included twelve schools from urban and rural areas. After attending a conference, teachers volunteered to participate and carry out the study. Data was then provided back to the researchers. All students began the year by choosing an appropriate colored overlay to use. The overlays were provided for the children to use as they chose.

At the end of the year, Wilkins et al. (2001) collected data on how many students were still using the overlays frequently. Sixty percent of the students were participated showed an increase in reading fluency with the use of a colored overlay. At the end of the study $52 \%$ of those students were still using the overlays. Students who continued to use the overlays had an increased reading rate of $13.3 \%$ at the beginning of the following school year, while those who discontinued use only showed an increase of $2.5 \%$. Colored 
overlays are an effective tool for increasing reading fluency rate, but must be used consistently in order to produce those positive results.

In 2002, Bouldoukian, Wilkins, and Evans completed a study examining the effect of colored overlays on the reading of individuals with Specific Learning Disabilities. The participants consisted of 33 children and adults. All participants had recently received an eye exam and had been treated accordingly. Even after treatment, the participants exhibited symptoms of visual stress when reading. It is important to note the recent eye exam as results of the study can be contributed to the colored overlay relieving the visual stress and not just masking a vision problem.

Bouldoukian et al. (2002) used an ABBA design. Two conditions were tested, reading with a chosen colored overlay and reading with a control filter. Half of the participants began and ended with the overlay, while the other half began and ended with the control filter. Participants read the same passage of jumbled words for each trial.

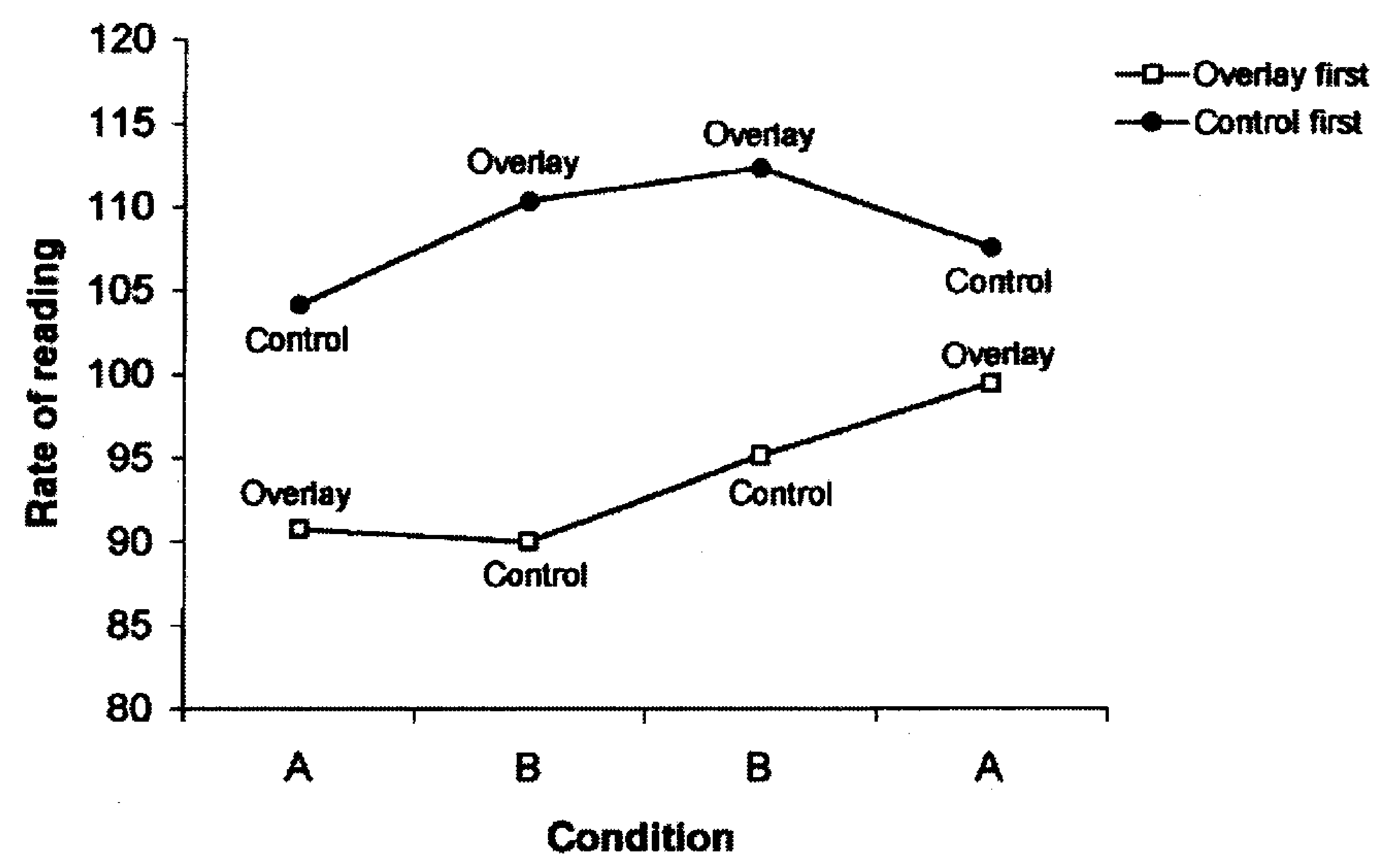

Figure 2. Bouldoukian et al. (2002) image depicting "the rate of reading test results, separated to illustrate the effects of order and of condition" (Bouldoukian et al., 2002, $58)$. 
The results showed two distinct patterns for the two groups participating. The group that began with the control filter showed an increase in reading rate from the first to the second trial. The researchers attribute this increase to the effect of the overlay and practice in reading the passage. The increase from the second to third trial not as great as the only difference between these two trials was more practice at reading the passage. The fourth trial shows the scores when readers returned to the control filter. It shows a decrease of reading rate to that below both of the trials with the overlay. It is, however, greater than the initial trial with the control filter. Bouldoukian et al. (2002) attribute this to the practice effect of having read the passage three time previously.

The group that began and ended with the colored overlay show a much different pattern of results. This group showed a decrease from trial one, colored overlay, to trial two, control filter. The researchers attribute this to being caused by "the removal of a treatment effect just out-weighed a practice effect." (Bouldoukian et al., 2002, 58) The third trial showed an increase in rate over both the first two trials. This is accounted for as an effect of having practice reading the passage. The final trial showed the highest rate in reading. This trial had the influence of the treatment of colored overlays and the practice effect.

The data for both groups was then combined to find any generalizations about the effect of colored overlays on reading fluency. Most of the participants had a higher rate of reading with the use of a colored overlay, an average of $4 \%$ increase. The researchers also asked the participants to choose which they preferred, the overlay or the filter. $66 \%$ of the participants preferred the overlay. For those $66 \%$, the increase in reading rate with 
the overlay was $5 \%$. For the participants who preferred the filter, their increase with the overlay was only an average of $1.7 \%$.

\section{Rate of reading}

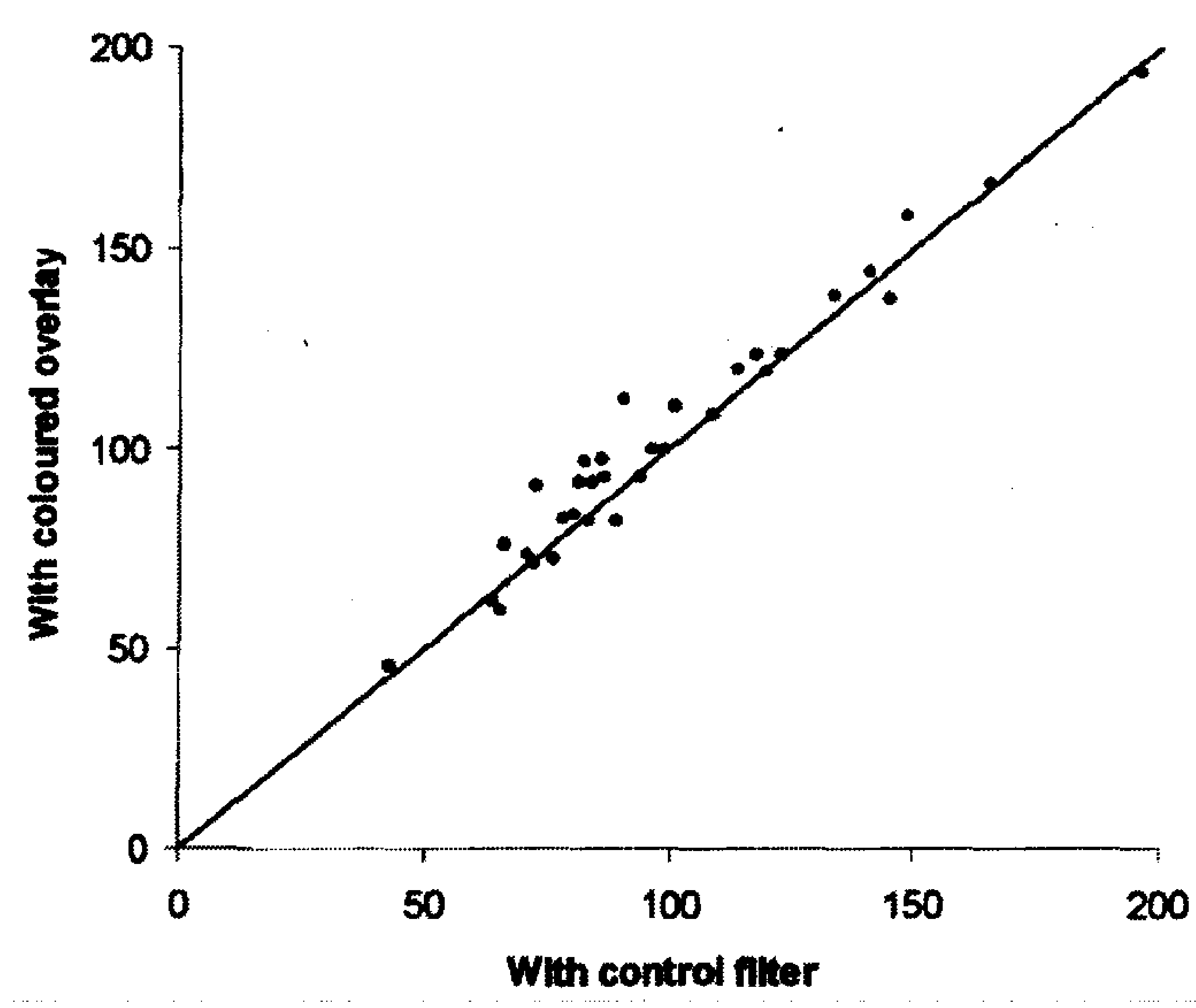

Figure 3. Bouldoukian et al. (2002) image depicting "Scatterplot showing, for each subject, the mean rate of reading with the coloured overlay plotted against the mean rate of reading with the control filter. Points above the diagonal line indicate a faster rate of reading with the coloured overlay" (Bouldoukian et al. 2002, 59).

The researchers worked to design an experiment that addressed any placebo effects on the results. First, preference for a colored overlay over the control filter was not statistically significant in order to affect the results. Second, 16 of the 33 participants had already been using and reporting benefit from colored overlays. Only 17 participants had never used an overlay before. Bouldoukian et al. explains:

If children continue to use a coloured overlay for a sustained period, then this suggests that they are more likely to be receiving a 'genuine' benefit, in addition to any placebo. A group of children who have only stated an immediate, initial, preference for an overlay might be expected to include a greater proportion of 'just placebo' cases than a group who had been using an overlay for longer. The 
results show that, unlike the immediate benefit group, the subjects who had been using their coloured overlay for a sustained period were indeed much more likely to demonstrate a faster rate of reading with this than with the control filter.

It is important to note that this study addresses the commonly criticized placebo effect of colored overlays. Many skeptics of colored overlays note that placebo most likely is at work with many students who participate in studies involving short assessment of the use of colored overlays. This study addresses the concerns and is able to show that the results are due to the overlay and not the placebo of motivation or preference.

Fletcher, et al. (2002), examined the federal definition of LD and the identification process involved. Fletcher et al. states:

The federal definition leads to assessment practices that are oriented toward eligibility and less toward intervention. The primary focus is on whether the child's IQ score is high enough relative to their academic levels, such that in practice, IQ tests are used to sort children. This approach makes it more likely that children will be identified as LD at older ages, effectively "preventing prevention" despite the burgeoning evidence that the most common form of LD, dyslexia, can be prevented in many children through early identification and intervention (Torgesen, this issue).

Fletcher et al. examines the different aspects that contribute to a learning disability. Other considerations along with IQ need to be taken into account when seeking to identify a student as having a disability. Academic, cognitive, and psychosocial characteristics factor into the performance of a child in reading. The researchers believe an intervention 
approach would be more appropriate and effective in addressing and preventing reading disabilities.

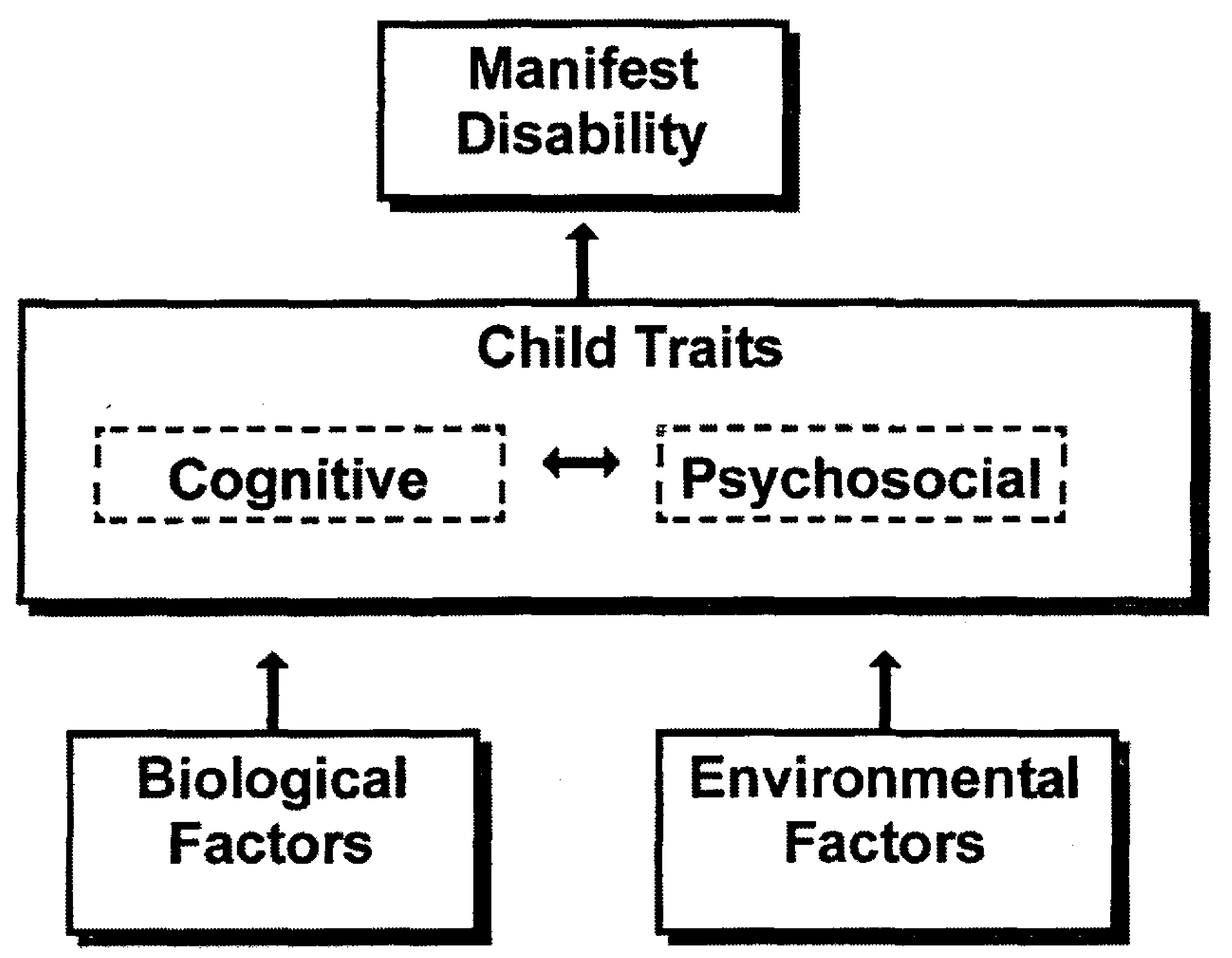

Figure 4. Fletcher et al. image depicting "Assessment framework for the biobehavioral systems approach" (Fletcher et al., 2002, 37)

Fletcher et al. goes on to cite two studies (Fletcher, Foorman et al., 1999 and Iovino, Fletcher, Breitmeyer, \& Foorman, 1999) in which the use of colored overlays did not show effectiveness as an intervention tool for students with word-level reading disabilities such as dyslexia. This is the only mention of colored overlays in the text. It is not explained further, but should be noted. The researchers focus on intervention strategies that address phonological awareness and processing.

In 2004, Waldie and Wilkins sought to answer questions in regard to the size of colored overlays and their effectiveness. The experiment was designed with four trials. Each participant read a passage of common words that were in a random order for all trials. The first trial was read without an overlay. The second trial was read with an 
Waldie and Wilkins (2004) image displaying "Mean values (and standard deviations) of reading speed (words per minute) for each of the four conditions of Study 1. (Waldie \& Wilkins, 2004, 59)

\begin{tabular}{lllll}
\hline & No overlay & A4 overlay & Small overlay & $\begin{array}{l}\text { Small overlay with } \\
\text { complementary surround }\end{array}$ \\
\hline Still using $(\mathrm{n}=21)$ & $76.4(26.6)$ & $85.1(24.7)$ & $89.3(30.2)$ & $85.9(25.5)$ \\
Stopped using $(\mathrm{n}=5)$ & $68.4(32.3)$ & $68.6(25.4)$ & $75.2(27.5)$ & $72.2(21.0)$ \\
\hline
\end{tabular}

Table 3

Waldie and Wilkins (2004) image displaying "Mean values (and standard deviations) of reading speed (words per minute) for each of the three conditions of Study 2. (Waldie \& Wilkins, 2004, 59)

\begin{tabular}{llll}
\hline & A4 overlay & Small overlay & Small overlay with complementary surround \\
\hline Still using $(\mathrm{n}=12)$ & $105.9(32.1)$ & $105.8(32.7)$ & $105.7(32.7)$ \\
Stopped using $(\mathrm{n}=6)$ & $101.8(28.2)$ & $101.3(35.8)$ & $104.5(26.0)$ \\
\hline
\end{tabular}

Williams, Kitchener, Press, Scheiman, and Steele (2004) wrote an article addressing the American Optometric Association's position on the use of colored overlays and lenses for the treatment of Meares-Irlen Syndrome. The authors summarized their interpretations of the available research and responded with three suggestions. The research was summarized in several points.

First, Williams et al. (2004) noted that many of the patients benefitting from colored overlays could be treated in other ways to eliminate the symptoms of visual stress making colored overlays or lenses unnecessary. The second point supports the first, stating that many of the current studies do not account for the possibility of an undiagnosed vision problem that corrective lenses or therapy would be a more appropriate treatment. The authors next noted that the research results differ from study 
to study. Some studies state that color choice is important while others focused on the use of only certain colors being beneficial.

Fourthly, the authors addressed the statistic that $25 \%$ of children using tinted lenses will need a color adjustment within the first year. This indicates that "Results of testing used to determine the most appropriate color are not repeatable." (Williams et al., $2004,721)$ The authors noted that colored overlays may be an effective intervention tool. However, they are not a cure for dyslexia. Williams et al. (2004) noted that "underlying physiological mechanism for the Irlen syndrome is still not known." Lastly, the authors addressed the concern that there were currently two methods of diagnosing Irlen syndrome that were considerably different.

The American Optometric Association responded with three statements of their position regarding colored overlays and lenses as a treatment for dyslexia or reading difficulties. First, a vision problem may be the cause of the reading difficulties and not Meares-Irlen Syndrome. Students should be tested and treated for any vision issues before Meares-Irlen syndrome can be diagnosed. Second, the AOA believes that more research in this area needs to be completed in order to find the actual effectiveness of colored overlays and lenses on reading. Lastly, the authors reiterated the importance of addressing any visual needs when a reading problem is present.

In 2005, Kriss and Evans completed a study looking for a relationship between dyslexia and Meares-Irlen syndrome. "Meares-Irlen Syndrome (MIS) is characterised by symptoms of visual stress and visual perceptual distortions that are alleviated by using individually prescribed coloured filters." (Kriss \& Evans, 2005, 350) Colored filters can be used in the form of colored overlays or tinted lenses that one wears when reading. The 
goal of this study was not to determine the effectiveness of colored overlays. The authors approached the study with the assumption that colored overlays do improve the reading speed of those with Meares-Irlen syndrome or visual stress symptoms as colored overlays are commonly used in diagnostic and screening process for this syndrome.

The study included 32 participants diagnosed as being dyslexic in the experimental group and 32 participants in the control group. The students ranged in age from 7 to 12 years old. Kriss and Evans (2005) hypothesized that a significantly larger portion of students with dyslexia would be identified as having Meares-Irlen syndrome than those in the control group as demonstrated by an increased reading rate with the use of a colored overlay. The students' reading rate was assessed using the Wilkins Rate of Reading Test (WRRT). This is not a passage of complete sentences, but a grouping of 15 common words repeated in a random order. Before being accepted as participants, the students were assessed to ensure that they were able to recognize and read all 15 words.

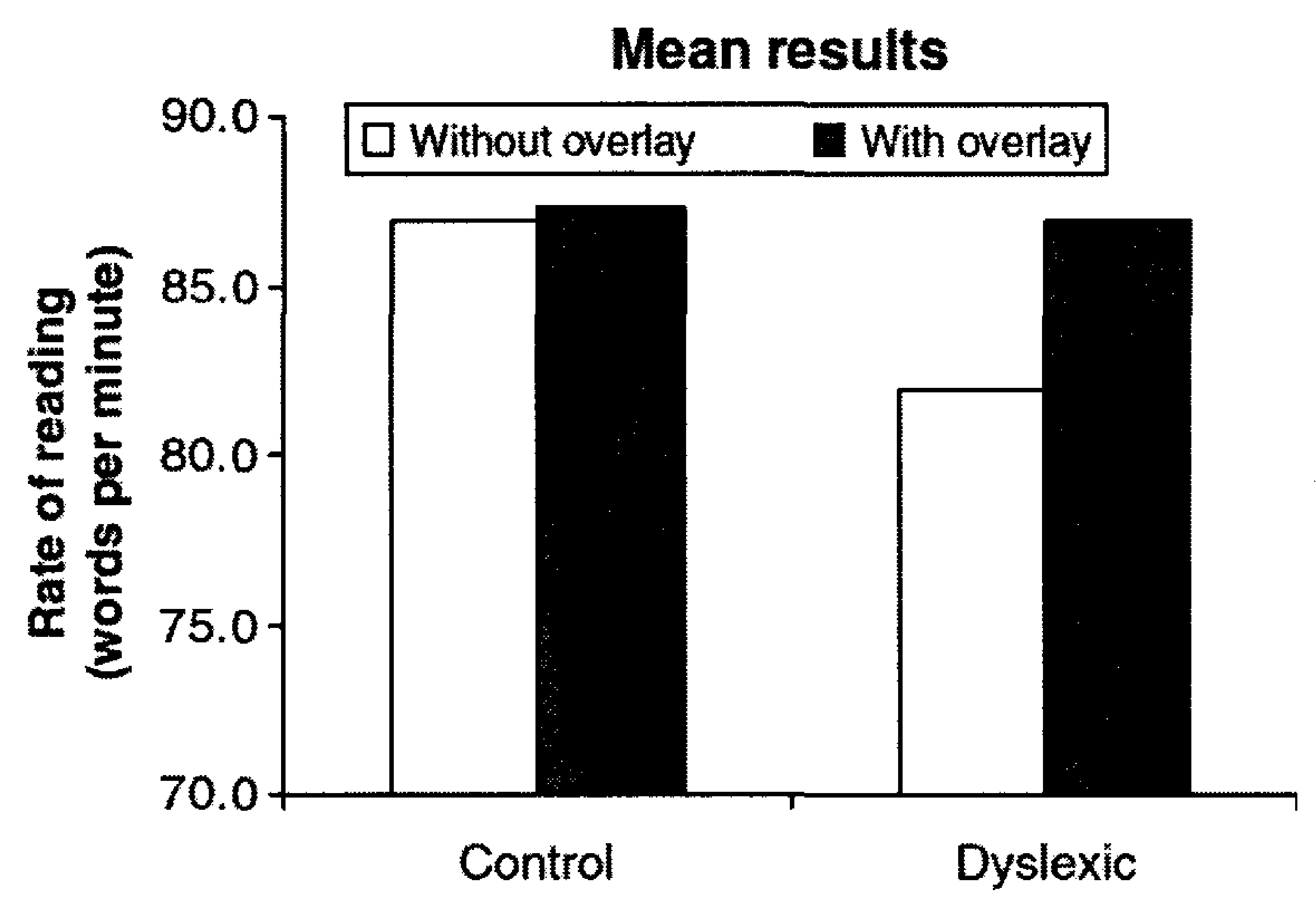

Figure 5. Kriss and Evans image depicting "Comparison of mean WRRT results for dyslexic and control groups with and without overlays" (Kriss \& Evans, 2005, 358). 
The results of the study did show a slightly higher portion of students in the experimental group benefitting from colored overlays than those in the control group. However, the difference was not found to be significant. Kriss and Evans (2005) noted, however, that the benefit from colored overlays was much greater for those with dyslexia than those without. The experimental group showed an increase in reading rate with the use of the colored overlays that was significant. The control group showed a slight increase in reading speed but not at a significant level. The authors were unable to support their hypothesis that Meares-Irlen syndrome is more prevalent in those with dyslexia than the general population.

\section{Current Research}

In 2006, Hollis and Allen looked at the effects of colored overlays for 58 adults with varying visual stress levels. Using a questionnaire and a test to measure perceptual distortions, the participants were placed in one of three groups: 20 normal, 20 MearesIrlen sensitive, and 18 borderline sensitive. Reading rates were calculated for all the participants with the use of a clear overlay and the use of a colored overlay. Participants placed in the borderline group were those who were identified through the questionnaire only as having previous symptoms of visual stress.

Table 4

Hollis and Allen (2006) image displaying "The mean reading speed (words per minute) and standard deviations for participants reading with and without their chosen overlay" (Hollis \& Allen, 2006, 568).

\begin{tabular}{llll}
\hline & Normal & Borderline & Meares-Irlen \\
\hline Color & $161(23.3)$ & $122(32.0)$ & $151(32.1)$ \\
Clear & $167(27.2)$ & $114(30.8)$ & $135(29.9)$ \\
\hline
\end{tabular}


The results showed that differences between the normal group and the other two groups were significant. No significant difference was found between the borderline group and the Meares-Irlen group. Hollis and Allen stated that the use of a questionnaire is not the most reliable method for identifying one as having Meares-Irlen Syndrome. The researchers concluded:

This paper indicates that the assessment of pattern glare and perceptual distortion immediately prior to measuring colour preference and reading speed is the most meaningful method of determining whether the use of a coloured overlay would be beneficial for those who experience glare and discomfort when reading. Whilst the reporting of previous symptoms may provide a useful indication that an individual may warrant further investigation we did not find these questions useful in predicting the potential benefit that a coloured overlay may have for a particular individual in terms of their performance on a visual task such as reading. (Hollis \& Allen, 2006, 570)

Newman Wright, Wilkins, and Zoukos (2007) conducted a study involving colored overlays and 26 participants diagnosed with multiple sclerosis. The researchers found that many patients with multiple sclerosis describe having symptoms of visual stress. They were unable to find any previous studies addressing this need with the use of colored overlays. The participants were asked to complete two different types of tests on more than one occasion. The first was a reading rate test to find the speed of reading. The second was a visual search assessment of accuracy and speed. The visual search involved finding targeted images on a page of circles. 
After completing a questionnaire about their symptoms, the participants were randomly placed in one of two groups. The first group used a colored overlay of their choice and the second group was assigned to use a grey overlay.

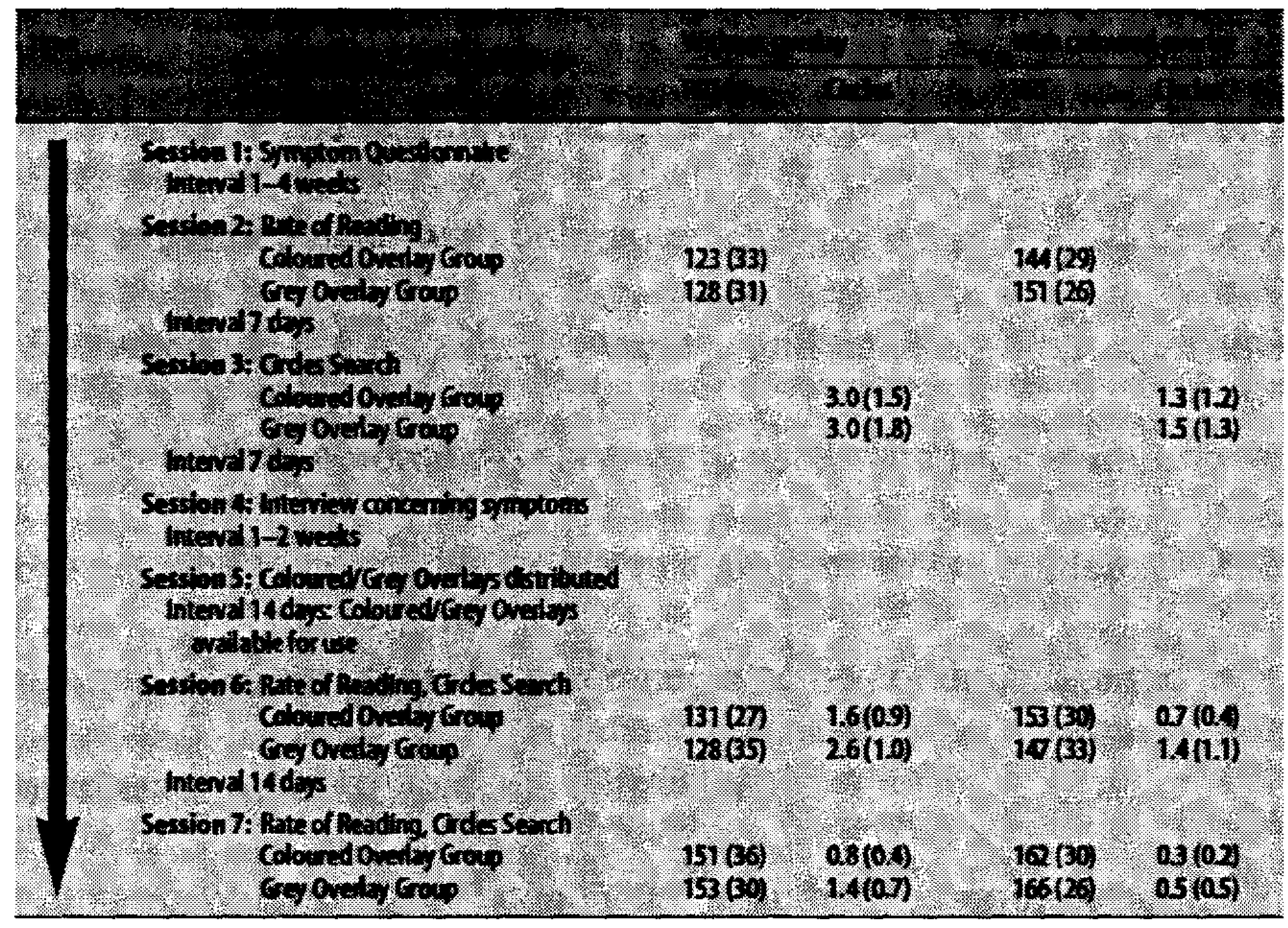

Figure 6. Newman Wright et al. (2007) image depicting "Time line showing the testing sessions, their content and the intervals between them...." (Newman Wright et al., 2007, 1732)

Newman Wright et al. (2007) concluded that the use of colored overlays did help to increase the performance on both the reading rate test and the visual search test of the participants. They noted that all but one of the participants showed a decrease in visual stress symptoms with the use of their chosen colored overlay. The authors noted "These improvements were experienced by patients in all diagnostic categories, perhaps surprisingly, given the inclusion of patients with a progressive disease course." (Newman Wright et al., 2007, 1734) This article is important to the research involving colored overlays because it shows that the effectiveness is not limited to only those with learning disabilities. Educators need to be willing to look for intervention tools that may apply to a 
variety of students. Though colored overlays are traditionally thought of as a tool for those with SRD, it can be used effectively with other groups of students.

In 2007, Trout and Epstein completed a study cataloging the effects of different types of non-medication interventions used to help increase the academic achievement of students with ADHD. The researchers examined 41 previously completed studies. Four of the studies examined dealt with colored overlays. Two of the studies showed no difference between the use of colored overlays and no use. One study showed an increase in comprehension when colored overlays were used. The final study showed that students with ADHD respond to colored overlays in a similar way to students without a disability. Trout et al. concluded that more research needs to be conducted in the area of nonmedication interventions for students with ADHD.

Smith and Wilkins (2007) conducted a study to examine whether the number of color choices offered is significant to the results of using colored overlays to increase reading fluency. The researchers used two systems of colored overlays. The first, Intuitive Overlays, are full paper size overlays with 30 color choices. The second, Eye Level Reading Rulers, only come in five colors and are much smaller. The reading rulers cover about two lines of text at a time and are designed to be moved down the page as the student reads. This highlights the text in color and allows the child to track where they are in a passage. Smith and Wilkins went through the process of having students pick a color from each of the systems and tests for a reading rate with each system and without the use of any colored overlay.

The 48 participants of the study were aged 7 to 8 and all had described having visual stress symptoms when reading. Smith and Wilkins (2007) found that with the use 
of the Intuitive Overlays, and more choices, the students showed an increase of more than $5 \%$ in their reading rate. With the Reading Rulers, no increase was found when compared to a baseline of reading without the use of a colored overlay.

Table 5

Smith and Wilkins image depicting "average number of words correctly read in 1 minute, under each condition" (Smith \& Wilkins, 2007, 337).

\begin{tabular}{ll}
\hline Overlay condition & Mean reading speed in wpm (SD) \\
\hline No overlay (white page) & $75.7(26.9)$ \\
Intuitive Overlay & $80.5(27.0)$ \\
Eye Lever Reading Ruler & $74.7(25.8)$ \\
\hline
\end{tabular}

Smith and Wilkins (2007) noted that the size of the overlay could have been a contributing factor. In order to account for this possible extraneous variable, the researchers did a comparison of reading rates using the full sized overlay from the Intuitive Overlays and one cut down to the size of the reading rulers. The comparison in reading rate when size was the only difference was not significant. The researchers believe that the size did not contribute the outcomes of their study.

The results of Smith's and Wilkin's (2007) study influenced the decision by this researcher to include sixteen colors as opposed to the basic set of eight colors from the National Reading Styles Institute. When implementing the intervention tool of colored overlays to improve reading fluency, schools need to provide a large enough group of colors from which students can choose. If color choices are limited, this study suggests that the positive results on of using colored overlays on reading fluency will also be limited. 
Ludlow et al. (2008) completed a study involving three experiments examining the benefit of colored overlays for children with autism spectrum disorders (ASD). The experiments looked for various aspects of the use of colored overlays in reading and pictures of objects. The first experiment examined the use of colored overlays chosen through a questioning process and reading rate. Participants were asked to choose a colored overlay based on how the overlay made the text appear. The questions addressed the letters appearing to move, blurred, too close together, and too bright or not bright enough. The results showed that a greater number of participants with ASD, than controls, had an increased reading fluency rate.

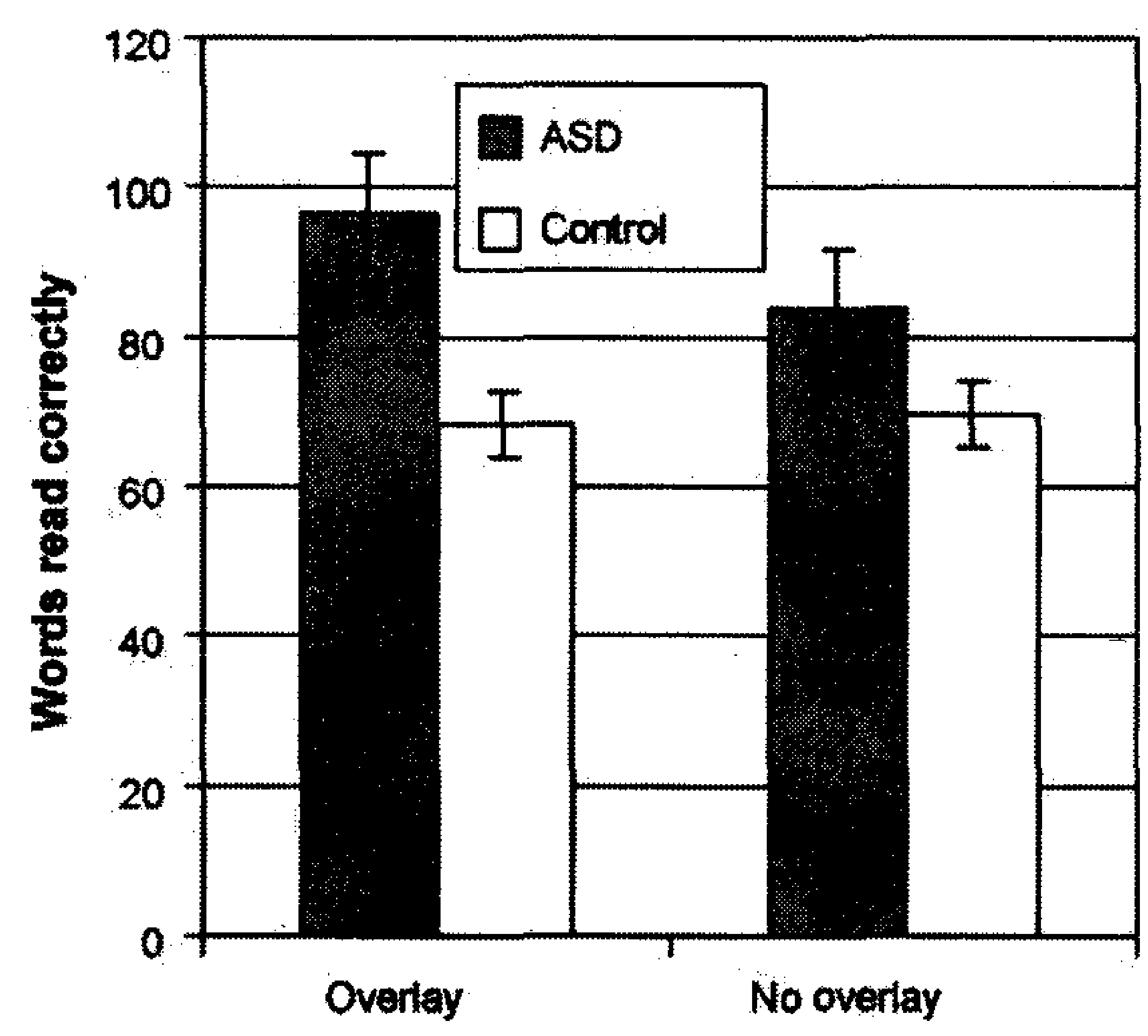

Figure 7. Ludlow et al. image depicting "number of words read in a minute with and without an overlay". (Ludlow et al., 2008, 503)

The second experiment was designed to test for a motivational influence on the effect of the colored overlay. This experiment compared the reading rate of choosing a colored overlay based on preference and one chosen based on text clarity. The results replicated the results in the first experiment. Colored overlays chosen based on text clarity showed an increase in reading rate, while colored overlays chosen based on 
preference did not show in increase in reading rate. This experiment shows the need for students using colored overlays to choose a colored based on how it makes the text appear, and not based on color preference.

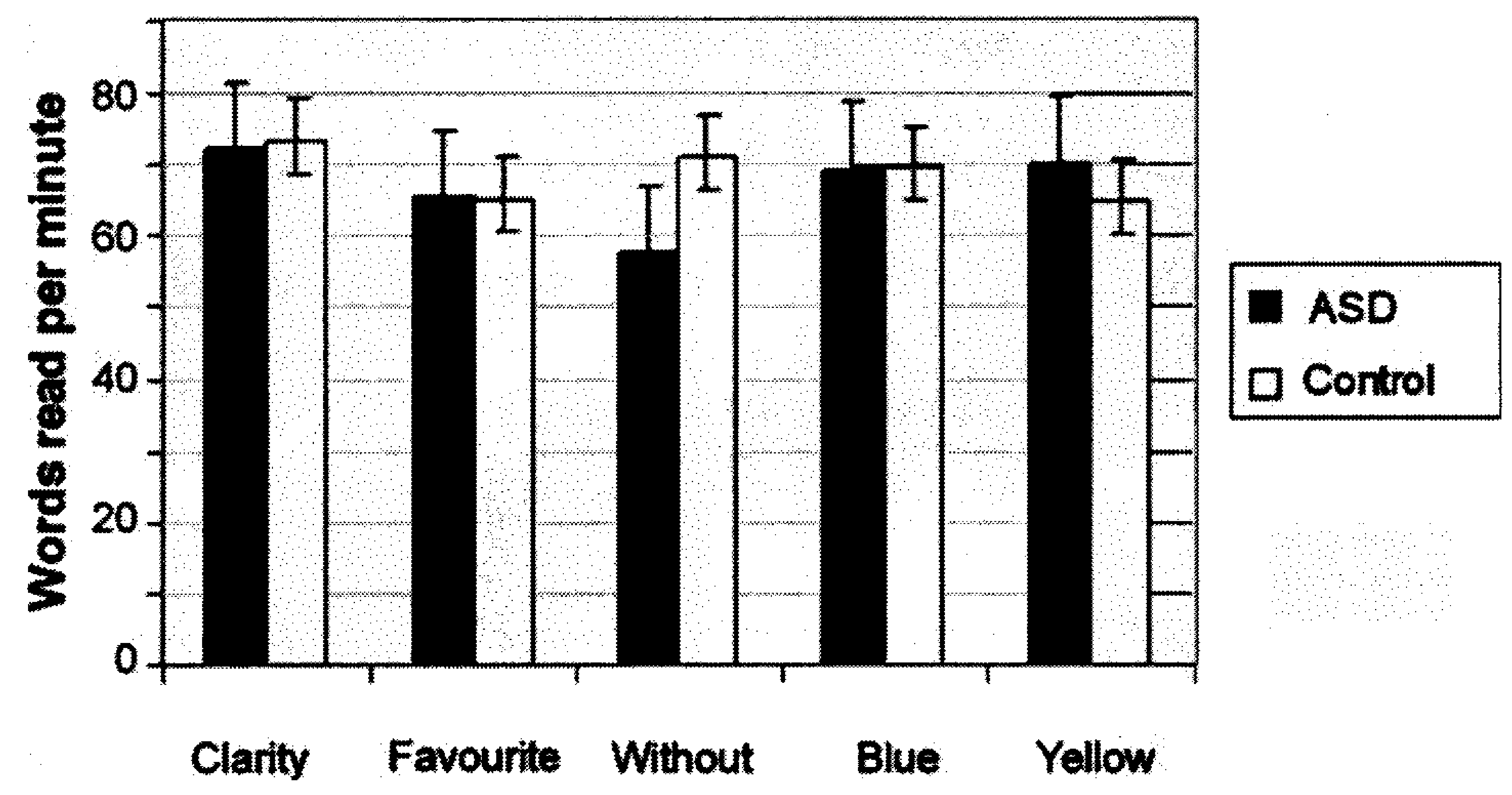

Figure 8. Ludlow et al. image depicting "number of words read per minute across the five overlay conditions." (Ludlow et al., 2008, 506)

The third experiment involved the use of colored overlays and changes in pictures. The results of this experiment showed an improvement when colored overlays were used. Ludlow et al. (2008) concluded:

The findings from all three experiments provide further experimental support for the suggestion that colored overlays can benefit many children with autism spectrum disorders. Importantly the gains observed in the current studies were significant only when overlays that improved clarity were selected and not when overlays were chosen on the basis of color preference. (Ludlow et al. 2008, 210) It is important for instructors to guide students in choosing an appropriate color based on clarity. A color chosen solely on preference will not produce the positive results on reading fluency as will a color chosen for clarity. 
In 2008, Dain et al. completed a study examining visual sensitivity of students with SRD to color and luminance. The study looked for differences in students with SRD compared to a control group of students with no reading difficulties. The experiment looked at a red-green color sensitivity and a blue-yellow color sensitivity. No difference was found for the red-green color. However, a difference between the two groups was found to be significant for the blue-yellow color. Dain et al. concludes, "The finding that blue-yellow sensitivity is raised in poor readers may provide a basis for understanding the success of the strategies used by color therapists for the alleviation of visual discomfort symptoms in poor readers." One strategy being referred to is the use of colored overlays.

In 2009, Winterbottom and Wilkins examined the lighting of a typical classroom and problems associated with it. They found that many of lighting aspects caused glares and reflections off surfaces in the classrooms. These glares and reflections can cause visual stress symptoms and discomfort in students in the rooms effecting reading. Overhead, fluorescent lights are the main culprit in most classrooms. Depending on the position of the room and windows, daylight can cause problems with glares and reflections. Many classroom now utilize the technology of projectors. These can also cause glares and reflections that can be distracting to students.

Winterbottom and Wilkins (2009) offer many suggestions on how to reduce some of these lighting issues in the classroom. They also recommend the use of colored overlays when reading. Colored overlays can help to reduce the glare on the page and thus relieve some of the stress caused by the lighting in the room. Winterbottom and Wilkins note that some of the benefits of colored overlays might be explained by their reduction of lighting discomfort in classrooms. 
Carbo (2010) examined the key elements of The Reading Styles Program; a reading program that helped one New York City middle school improve their rating from the $12^{\text {th }}$ percentile to the $90^{\text {th }}$ in one year. After the second year of implementation, they were in the $99^{\text {th }}$ percentile. The program focused on addressing the needs of at-risk learners by providing four key interventions for students. First, teachers match students' reading styles to assignments in reading and comprehension. Second, passages that are more difficult are recorded for students to listen to before attempting to read. This prepared the students for reading and reduced frustration levels. Third, a variety of reading choices were provided to meet the interests of all students. Fourth, the physical environment was considered and adjusted to the needs of the students. This included providing a comfortable and informal space for reading with soft lighting. Colored overlays were also used to help reduce signs of visual stress. The primary goal of the program is to create an enjoyment for reading in students. When students enjoy reading, they will want to do it more and thus improve their reading skills.

In 2010 , Northway et al. completed a study to determine if colored overlays would reduce visual distractions for those identified as being dyslexic. Their study included ten adults with dyslexia and had a control group of ten adults without dyslexia. They sought to find a way to help those with dyslexia respond to visual discomfort in a way that would be normal for one without dyslexia. They concluded that the use of colored overlays creates this normality for those with dyslexia.

The researchers used an ABBA format, finding two baselines and two rates with the treatment. With and without the use of colored overlays, those with dyslexia had a much lower reading rate than those without dyslexia. The use of colored overlays helped 
to close the gap in achievement between the two groups. Without an overlay, those with dyslexia and the control group read at a rate of 66 and 112 words per minute respectively. When a colored overlay was added, the experimental group raised their rate to 84 words per minute, while the control group had a slight drop in reading rate to 106 words per minute. 


\section{CHAPTER III: METHODOLOGY}

\section{Presentation of the Problem}

This study was initiated to address the needs of a particular population of students at Eaton Middle School. Students identified as having a cognitive disability are required in regular and special classroom settings to be able to read text. The school sought interventions that are effective, affordable, and easy to implement. Colored overlays are an intervention tool that are affordable and easy to implement. The researcher sought to determine if it would be an effective tool for students with cognitive disabilities.

Through examining the research conducted on the use of colored overlays, a gap was found in the types of populations studied. No study involving colored overlays was found that addressed the population of students identified as having a cognitive disability. The researcher designed an experiment to provide information to the school and begin to provide research that addressed the use of colored overlays and the reading fluency of students with cognitive disabilities.

\section{Presentation of the Hypotheses}

This project will seek to show a causal relationship between the use of colored overlays and an increased reading fluency rate in students with cognitive disabilities. The researcher hypothesizes that the use of colored overlays will increase the reading fluency 
rates of middle school students identified with a cognitive disability. This study will also seek to replicate previous research involving colored overlays and students with Specific Reading Disabilities. The researcher hypothesizes that the control group will show an increase in reading level with the use of a colored overlay. Lastly, this study will seek to show that students with cognitive disabilities respond in a similar way to the intervention as do students with Specific Reading Disabilities.

\section{Participants}

This study included two groups of participants. The first group is the experimental group. This group consisted of the entire population of students with cognitive disabilities at Eaton Middle School. The population included nine students in sixth through eighth grade. The students ranged in age from 12 to 15 years old. The group was comprised of five males and four females. There were two sixth graders (both male), two seventh graders (one male, one female), and five eighth graders (two male, three female). Five of the students in group one qualify for free lunch. Four of the students participate in the regular education curriculum and are required to take the Ohio Achievement Assessment. The other five students were in a self-contained classroom with a modified curriculum. Those students meet the requirements of the Ohio Achievement Assessment through an alternate assessment process.

The control group was comprised of nine students from Eaton Middle School identified as having a Specific Reading Disability. The students ranged in age from 12 to 15 years old. The group was comprised of six males and three females. When selecting students for group two, the researcher gave priority to grade level over gender when 
matching students with the experimental group. No other female students met the requirements of the study for that particular grade level (eighth) so a male was selected to participate based on grade level and socioeconomic status. The group contained two sixth graders (both male), two seventh graders (one male, one female), and five eighth graders (three male, two female). Five of the students in group two qualify for free lunch. All the students in group two participate in some or all the regular education curriculum and are required to take the Ohio Achievement Assessment.

\section{Instruments}

Reading passages were taken from Dr. Roger C. Farr's Oral Reading Fluency Assessment book. This is a book published by Harcourt for classroom use in calculating reading fluency rates of students. The book provides four to six leveled reading passages for first through sixth grade. Students read passages at their independent reading level as identified in the present levels data of their IEPs.

Students were able to choose from 16 different colored overlays. The colored overlays were produced by the National Reading Styles Institute. The overlays have a matte finish to reduce glare. The colors included and were presented in the following order: pale rose, yellow, turquoise, peach, pink, gray, aquamarine, blue, rose, gold, purple, light peach, red orange, pale blue, light blue, and medium blue.

\section{Variables}

The independent variable in this study is the use of a colored overlay when reading. Students will be asked to read with and without the colored overlay. The 
dependent variable is the reading fluency rate of the three trials. There are many controlled variables in this study. Students read all three passages during the same time frame, within a five minute window. All reading passages were on the same reading level, were around the same length, and used the same font type. The researcher tried to account for and avoid all extraneous variables with the use of an A-B-A design and by applying the controlled variables. The A-B-A design eliminated the possibility that increasing scores could be contributed to a student beginning to read faster as the trials progressed. Two baselines would ensure that any difference in scores is caused by the treatment. One possible extraneous variable the researcher is unable to control would be the possibility of a particular student's familiarity with the subject and vocabulary of one reading passage versus another reading passage. This would vary from student to student and the researcher does not believe it would be considerable enough to influence the validity of the results of the trials.

\section{Procedures}

Before beginning, the researcher gained permission from the Cedarville University Institutional Review Board, the Eaton Middle School building principal, and the Eaton Community Schools district superintendent to complete the research project. The researcher then worked closely with the intervention specialists at Eaton Middle School to select the appropriate participants for group two. Passive consent forms were sent home with students who were selected to participate. Parents were given at least a week to respond to the passive consent letters before trial sessions began. Students were also asked to sign a form indicating their willingness to participate in the project before 
beginning their trial sessions. No parents or students refused consent or willingness to participate.

Group one consisted of the entire population of Eaton Middle School students identified as having a cognitive disability. This included nine students from grades $6^{\text {th }}$ to $8^{\text {th }}$. When selecting participants for group two, the researcher first narrowed the group to students identified with a Specific Reading Disability. Identification was determined through IEP data and goals. This group was further narrowed as the researcher sought to match students in group two closely to students in group one. Students were matched by grade level, then gender, and lastly socioeconomic status. The researcher was unable to match gender for one participant. Socioeconomic status was determined by student qualification for free or reduced lunch.

After all students were selected, passive consent forms were sent home. After one week the trial sessions began and took place over a two week period in May of 2011. Students participated in the trial sessions during their assigned study hall period so as to avoid missing core content area instruction. Each session lasted about 10 to 15 minutes. The sessions began with a brief explanation of the requirements of the session and gaining the permission of the student's willingness to participate. The explanation included describing the process in choosing a colored overlay and informing the participant that he or she would be asked to read three separate passages aloud to the researcher. Students then participated in the color selection process followed by the three timed running records to determine reading fluency rate. Each running record was one minute in length. 
To select a color, students were presented with two colors at a time to compare to one another. Each colored overlay was placed over an identical reading passage. The student was asked to look at the overlays side by side and pick a preferred color. The preferred color was retained, while the other was removed. A third color replaced the removed color and the participant was again asked to choose a preferred color. This process continued until all 16 colored overlays had been viewed and evaluated by the student with the most preferred color remaining. The color chosen would be used in the second trial reading.

Before comparing the overlays, students were instructed to look closely at the different colors and to choose based on how the color made the text appear and not based on which might be a favorite color. Each time the student was presented with two colors, the researcher prompted, "Pick the color that makes the passage the easiest to read. Which color makes the words the clearest?"

After choosing a preferred color, the student began the three trials of timed running records. The first trial, the student was presented with a reading passage on plain white paper without a colored overlay. The researcher used a stop watch to time one minute of the student reading. After reading the passage for a minute, the student was asked to stop. The second trial included the chosen colored overlay placed over a reading passage for the student to read. The student read for one minute as with the first trial. For the last trial, the student was again presented with a reading passage on plain white paper without a colored overlay. Each trial was timed for one minute. During each trial, the researcher made note of any words misread. The reading passages were different for each of the three trials, but all were on the same reading level. Each student read three 
passages on their determined independent reading level. Reading levels were obtained through IEP documentation.

After the student participated in the three trials, the researcher calculated the reading fluency rate for each trial and recorded the score. Reading fluency rate was found by subtracting reading errors from total number of words read. Data was then entered into the PASW Statistics 18 program for analysis. 


\section{CHAPTER IV: RESULTS}

The Experiment

Students were placed in one of two groups based on their Special Education identification category. Group one, the experimental group, consisted of students identified as having a Cognitive Disability. Group two, the control group, was comprised of students with Specific Reading Disabilities. Each group followed the same method of participation in the experiment. The experiment followed an A-B-A design to test for reversal. All students were asked to participate in three reading fluency rate trials. The first and last trial did not have the treatment applied to provide baselines. Students read a passage printed in black on plain white paper. The second trial applied the treatment of a colored overlay. Students read a passage with a colored overlay placed over the black print on plain white paper. Data was collected and recorded for all three trials for each participant.

Before reading, the students followed the designated process for choosing a colored overlay to use in the second trial. Students chose one of sixteen colors by comparing the overlays two at a time. Once a color was chosen, the reading fluency rate trials began. The entire process was completed during one session lasting around 10 to 15 minutes for each participant. 


\section{Analysis}

Data was analyzed with the use of the PASW Statistics 18 program to run multivariate tests of repeated measures ANOVA on the three reading fluency rate trials. The data included the results from all trial participants, 9 students with cognitive disabilities (group one) and 9 students with Specific Reading Disabilities (group two). Group one had means of $85.11,94.44$, and 81.00 respectively on trials one through three. Group two's trial means were $80.22,94.67$, and 84.11. Both groups showed an increase in reading fluency rate from trial one to trial two and a decrease from trial two to trial three. Ideally, reading fluency rate would rise with the application of the treatment and then fall when the treatment was removed. This trend was true for both groups of students. The means show that this research replicated past studies (Northway et al., 2010; Dain et al., 2008) involving students with specific reading disabilities and the use of colored overlays.

The mean scores would appear to confirm the hypothesis that the use of colored overlays increases reading fluency rate in middle school students with cognitive disabilities or Specific Reading Disabilities. Multivariate tests of repeated measure ANOVA were run to test the significance of these results. The data was first analyzed using within-subject factors of both group one and two. The multivariate tests showed a significant difference between the three trials: $\mathrm{p}<.001$. The significance level confirms the hypothesis. 


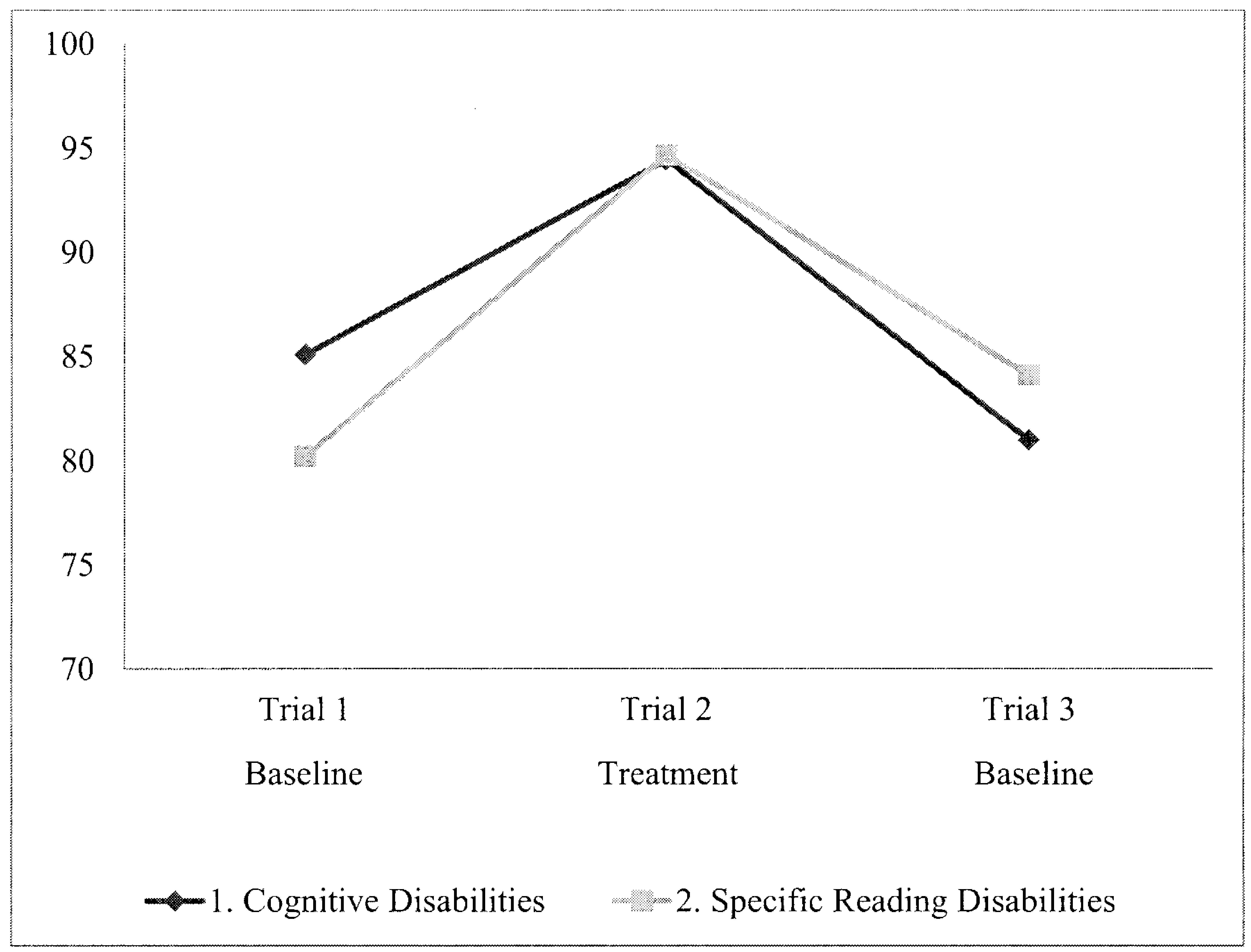

Figure 9. Line graph of Mean trial one, two, and three scores for groups one and two

Table 6

Mean Trial one, two, and three scores for groups one and two

Trial

\begin{tabular}{ccccc}
\hline$\underline{\text { Group }}$ & $\underline{\mathrm{n}}$ & $\underline{\text { Trial 1 }}$ & $\underline{\text { Trial 2 }}$ & $\underline{\text { Trial 3 }}$ \\
$\begin{array}{c}\text { 1. Cognitive } \\
\text { Disabilities }\end{array}$ & 9 & 85.11 & 94.44 & 81.00 \\
$\begin{array}{c}\text { 2. Specific Reading } \\
\text { Disabilities }\end{array}$ & 9 & 80.22 & 94.67 & 84.11 \\
\hline
\end{tabular}

When analyzing group one's data separately, the multivariate tests showed a significant difference between the three trials with a level of $p<.029$. This confirms the 
hypothesis that colored overlays increase the reading fluency of students with cognitive disabilities. Though the sample size is small, the results met the researcher's designated alpha level of $\leq .05$ to determine significance. A larger sample size, following similar results, would meet a more strenuous alpha level.

The tests of Between-Subjects effects showed that the groups behave in the same manner, $\mathrm{p}=.982$. There is no significant difference between the performance of group one and group two. This confirms the hypothesis that the students with cognitive disabilities will respond in a similar way to the intervention of colored overlays as the students with Specific Reading Disabilities.

Each group consisted of the same number of participants in each grade level: two sixth graders, two seventh graders, and five eighth graders. Each student in the control group was chosen to match as closely as possible to a student in the experimental group in the areas of grade level, gender, and socioeconomic status. There is no need to look for comparisons between the two groups in these areas due to the careful matching.

When looking at the difference between male and female participants, the females reading fluency rate was higher than male rates in both groups. The female participants' mean scores for the three trials were $105.57,126.86$, and 111.29 . This was a $20 \%$ increase from trial one to trial two and a $12 \%$ decrease from trial two to trial three. The male participants' mean scores for the three trials were 68.09, 74.00, and 64.27. This was an $8.7 \%$ increase from trial one to trial two and a $13 \%$ decrease from trial two to trial three. A larger sample size from a broader population would be needed to draw valid conclusions. The researcher did not seek to draw any conclusions from this data as it was not the focus of the study. 
When looking at the individual scores of the students in group one, a variety of responses to the treatment can be seen. Some students did not show any change to the treatment. The use of colored overlays may be a successful intervention tool for many students with cognitive disabilities; however, it may not increase the reading fluency of others. A study involving more participants would need to be conducted to determine how broad the effectiveness of this intervention tool is for students with cognitive disabilities.

The researcher believes that the results of the study are valid. This study was designed to eliminate as many extraneous variables as possible. The A-B-A design gathers two baselines, one before the application of the treatment and one after the treatment is removed. By using this design the researcher was able to test for a reversal. A reversal was evident in the data collected. This supports the conclusion that the increase in reading rate was indeed due to the application of the treatment, colored overlays. If an A-B-A design was not used, the increased reading rate could have been contributed to a student getting into the flow of reading as the session progressed. A reversal after the treatment is removed allowed the researcher to conclude that the treatment was the cause for an increased reading rate.

A second extraneous variable accounted for in the study is differences in time of day or circumstances of a particular day influencing the results of the reading fluency rate trials. All data for each participant was collected during one 10 to 15 minute session. Fluency rates were gathered in back to back trials without interruption. This ensured that any outside influences of one particular school day did not impact each trial in a different 
way, as all trials for a participant were conducted on the same day during the same time period.

This project sought to answer questions specific to one middle school. It was able to determine which students benefited from the use of a colored overlay and which colored was preferred by the students. The results from this study will be able to be implemented immediately in the classrooms of the students involved in the study. Future studies would be able to answer general questions in regards to the use of colored overlays with students with cognitive disabilities. A study involving a larger group of participants and broader range of ages will be able to determine how effective this intervention tool is for this population of students. 


\section{CHAPTER V: SUMMARY}

The results of this project have produced more questions than they answered. The researcher was able to complete her goal of providing specific information for one particular middle school. However, more research needs to be completed to begin answering questions of how broad and pervasive these results might be for the rest of the population of students with cognitive disabilities.

The researcher began this study with the hopes of finding out if using colored overlays with students with cognitive disabilities is an effective tool for increasing reading fluency. The experiments were designed to calculate a reading fluency baseline before and after the treatment of the overlays was applied and then removed. If colored overlays are an effective tool, then the reading fluency rate for the baselines would be lower than the rate of reading with a colored overlay. The data showed that this was the case. For both the control and experimental group, there was a significant increase in reading fluency rate when a colored overlay was used.

There are several implications to the results of this study. First, Eaton Middle School now has specific information to guide intervention decisions for classroom use. The students who participated have gone through the process of choosing the appropriate color and can begin to use that colored overlay for completing classroom assignments or when reading for pleasure. Teachers will now know which students benefit from this 
intervention tool and how to implement it. Using a colored overlay in the classroom setting is a simple task once the student has chosen a color. The school may decide whether to provide the students with the colored overlay to carry from class to class and home, or the school may decide to have colored overlays available during each class period. The first solution would be beneficial as it would allow the student to always have access to the colored overlay, even at home. However, the student would have to be responsible in remembering to use the overlay and keeping track of it. With the second solution, the school would not have to worry about students losing their overlays. Yet, teachers would have to remember to pass out and collect the overlays and students would not have access to the overlays when completing assignments outside of school.

The second implication for Eaton Middle School is in regards to the control group. The control group consisted of students identified as having a Specific Reading Disability. The majority of special education students at EMS have this identification. Only nine of these students participated in the project. The results showed that the use of colored overlays is an effective tool to increase reading fluency rates for these students. The rest of the population of students with SRD at Eaton Middle School would benefit from going through the process of choosing an appropriate colored overlay for use in the classroom. This process would take about ten minutes per child and could be completed at the beginning of the school year. This recommendation, along with the results of the study, will be passed along to the intervention specialists and principal at Eaton Middle School.

Though the sample size was very small, the researcher believes that it was large enough considering the purposes of her project. The researcher used the entire population 
of students with cognitive disabilities from Eaton Middle School. The initial purpose of the project was to provide information to the school regarding this population. The results of the project provided the school with information on which students benefited from the use of colored overlays and which colored overlay was appropriate for each student. This information will be provided to the students' teachers so that the intervention can be implemented at the beginning of the 2011-2012 school year. The project took place at the end of the previous school year and thus implementation will wait until school resumes.

After gathering preliminary results from the project, the researcher briefly discussed the implications for instruction with the district superintendent. He has requested that final conclusions be shared with the middle school staff and extended to other buildings in the district. The project was completed with students in $6^{\text {th }}$ through $8^{\text {th }}$ grade; however, the researcher believes the positive results would also be found for other grade levels. In the 2011-2012 school year, the researcher will be working with students in the districts $3^{\text {rd }}$ to $5^{\text {th }}$ grade building. She plans on implementing the use of colored overlays with students in that building who are identified with cognitive or specific reading disabilities and gathering more data on the effectiveness of this intervention tool.

If the researcher were to complete this project again, she would change a few elements. The researcher would have preferred to have had a larger population of students to work with. However, being able to use the entire population was beneficial in providing information to the school district. The researcher would also extend the study to include students in the high school and upper elementary school, as they would also benefit from the information provided. The researcher would also have completed the study at the beginning of the year so that information gathered through this process would 
be able to be applied immediately. However, the information will be passed along to the appropriate teachers so that implementation can begin as soon as school resumes after the summer break.

In the future, the researcher would like to be able to conduct a more extensive study on the use of colored overlays and the reading fluency of students with cognitive disabilities. She would like to expand the study to include a wider range of grade levels and include are larger sample size. To do this, other school districts would have to be involved in the study. Having worked with students with a variety of disabilities, including cognitive disabilities, the researcher is committed to finding effective, affordable, and easy to implement intervention tools for use in her own classroom and in the classrooms of other teachers. 


\section{References}

Braddock, D., Rizzolo, M. C., Thompson, M., \& Bell, R. (2004). Emerging technologies and cognitive disability. Journal of Special Education Technology, 19(4), 49-56.

Bouldoukian, J., Wilkins, A. J., \& Evans, B. J. W. (2002). Randomised controlled trial of the effect of coloured overlays on the rate of reading of people with specific learning difficulties. Ophthalmic and Physiological Optics, 22(1), 55-60. doi:10.1046/j.14751313.2002.00002.x

Carbo, M. (2010). What helps at-risk adolescent readers? Reading to Learn, 67(6), 1-4.

Dain, S. J., Floyd, R. A., \& Elliot, R. T. (2008). Color and luminance increment thresholds in poor readers. Visual Neuroscience, 25(3), 481-486. doi:10.1017/S0952523808080565

Fletcher, J. M., Foorman, B. R., \& Boudousquie, A. (2002). Assessment of reading and learning disabilities: A research-based intervention-oriented approach. Journal of School Psychology, 40(1), 27-63.

Hollis, J., \& Allen, P. M. (2006). Screening for Meares-Irlen sensitivity in adults: Can assessment methods predict changes in reading speed? Ophthalmic and Physiological Optics, 26(6), 566-571. doi:10.1111/j.1475-1313.2006.00401.x

Irlen Institute. Shop our store-colored overlays. Retrieved from http://irlen.com/index.php?s=overlays 
Kriss, I., \& Evans, B. J. W. (2005). The relationship between dyslexia and meares-irlen syndrome. Journal of Research in Reading, 28(3), 350-364. doi:10.1111/j.14679817.2005.00274.x

Ludlow, A. K., Wilkins, A. J., \& Heaton, P. (2008). Colored overlays enhance visual perceptual performance in children with autism spectrum disorders. Research in Autism Spectrum Disorders, 2(3), 498-515. doi:10.1016/j.rasd.2007.10.001

Newman Wright, B., Wilkins, A. J., \& Zoukos, Y. (2007). Spectral filters can improve reading and visual search in patients with multiple sclerosis. Journal of Neurology, 254(12), 1729-1735. doi:10.1007/s00415-007-0648-y

Northway, N., Manahilov, V., \& Simpson, W. (2010). Coloured filters improve exclusion of perceptual noise in visually symptomatic dyslexics. Journal of Research in Reading, 33(3), 223-230. doi:10.1111/j.1467-9817.2009.01409.x

O'Connor, P. D., Sofo, F., Kendall, L., \& Olsen, G. (1990). Reading disabilities and the effects of colored filters. Journal of Learning Disabilities, 23(10), 597-603, 620.

Smith, L., \& Wilkins, A. (2007). How many colours are necessary to increase the reading speed of children with visual stress? A comparison of two systems. Journal of Research in Reading, 30(3), 332-343.

Trout, A. L., \& Epstein, M. H. (2007). A review of non-medication interventions to improve the academic performance of children and youth with ADHD. Remedial and Special Education, 28(4), 207-226. 
Waldie, M., \& Wilkins, A. (2004). How big does a coloured overlay have to be? Ophthalmic and Physiological Optics, 24(1), 57-60. doi:10.1046/j.14751313.2003.00169.x

Wilkins, A. J., Lewis, E., Smith, F., Rowland, E., \& Tweedie, W. (2001). Coloured overlays and their benefit for reading. Journal of Research in Reading, 24(1), 41-64. doi:10.1111/1467-9817.00132

Williams, G. J., Kitchener, G., Press, L. J., Scheiman, M. M., \& Steele, G. T. (2004). The use of tinted lenses and colored overlays for the treatment of dyslexia and other related reading and learning disorders. Optometry - Journal of the American Optometric Association, 75(11), 720-722. doi:10.1016/S1529-1839(04)70226-2

Winterbottom, M., \& Wilkins, A. (2009). Lighting and discomfort in the classroom. Journal of Environmental Psychology, 29(1), 63-75. doi:10.1016/j.jenvp.2008.11.007 